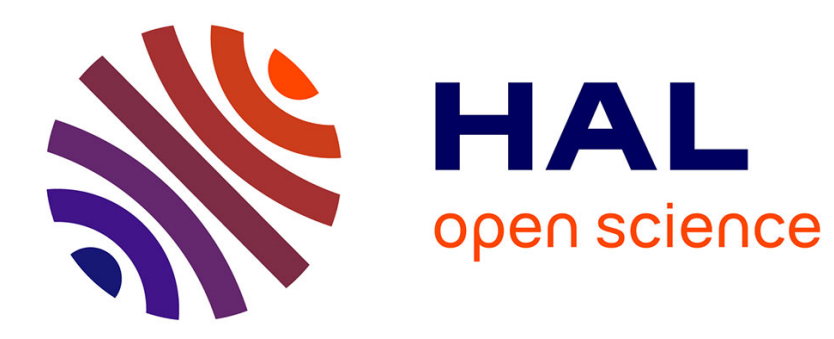

\title{
Four-Membered Rings With Two Oxygen Atoms
}

Alexandre Pradal

\section{To cite this version:}

Alexandre Pradal. Four-Membered Rings With Two Oxygen Atoms. Comprehesive Heterocyclic Chemistry IV, 2021, 10.1016/B978-0-12-818655-8.00152-9 . hal-03358834

\section{HAL Id: hal-03358834 https://hal.science/hal-03358834}

Submitted on 29 Sep 2021

HAL is a multi-disciplinary open access archive for the deposit and dissemination of scientific research documents, whether they are published or not. The documents may come from teaching and research institutions in France or abroad, or from public or private research centers.
L'archive ouverte pluridisciplinaire HAL, est destinée au dépôt et à la diffusion de documents scientifiques de niveau recherche, publiés ou non, émanant des établissements d'enseignement et de recherche français ou étrangers, des laboratoires publics ou privés. 


\title{
Four-Membered Rings With Two Oxygen Atoms
}

\author{
Alexandre Pradal, Sorbonne Université, Paris, France
}

(C) 2021.

Email address: alexandre.pradal@sorbonne-universite.fr (A. Pradal)

\section{Introduction}

There are two possible isomers for the four-membered ring compounds possessing two oxygen atoms: 1,2-dioxetanes and 1,3-dioxetanes. Both of them are named after the position of the oxygen atoms inside the ring structure. Among all the possible dioxetanes that have been reported in the literature, we shall focus on the structures 1-8 as they have been the topic of some research papers between 2008 and 2019 (Scheme 1). 1,2-Dioxetanes of structure 1-4 have been isolated in stable forms and will be detailed in this chapter. Firefly 1,2-dioxetanone $\mathbf{5}$ is prepared in living organisms from firefly luciferin in the presence of oxygen and enzymes and decomposes readily showing a bioluminescence phenomenon (yellow-light emission) in some firefly species. 1,3-Dioxetanes of structure 6-8 have been only postulated as reaction intermediates. Even so, few theoretical elements will be mentioned regarding calculated physical data.

Overall, this topic has previously been the subject of book chapters in the CHC collection in $1984,{ }^{1}$ in $1996^{2}$ and in the latest edition in 2008. ${ }^{3}$ In the first edition in 1984, the chapter dealing with dioxetanes was also reporting literature on all the other four-membered rings that were including two heteroatoms. The second and third editions possessed chapters exclusively dedicated to four-membered rings with two oxygen atoms. Likewise, this chapter will focus on those types of heterocycles with updates concerning their physical and chemical properties, reactivity, synthesis and applications. Most of the updates will be also focused on the preparation and applications of dioxetanes as most of the work dedicated to their characterization, physical properties and reactivity has been widely reported before 2008 .

\section{Theoretical methods}

\subsection{Studies on 1,2-dioxetanes}

As most of the four-membered rings, 1,2-dioxetanes possess high strain energy making them rather unstable. When they decompose into the corresponding ketones, they liberate energy accompanied with light emission. This is the reason why most of the work reported on 1,2-dioxetanes during the last decade, concerns the preparation and study of chemiluminescent molecules. ${ }^{4}$ Those compounds can be exploited for the development of detectors for bioassays and in particular for immunoassays in the field of medical diagnosis.

Significant work has been dedicated to theoretical studies of the decomposition of 1,2-dioxetanes. The reader is being advised to have a look at the previous chapters on 1,2-dioxetane within the Comprehensive Heterocyclic Chemistry collection to have an historical background of the different mechanistic theories proposed. ${ }^{1-3}$ The following subsections will be dealing with the most recent developments in the theoretical studies performed on 1,2-dioxetanes.

\subsubsection{Theoretical studies on the decomposition of 1,2-dioxetanes 1}

2.1.1.1 Mechanistic studies on the decomposition of unsubstituted 1,2-dioxetane

Within the past 12 years, thermal decomposition of the simplest dioxetane (1,2-dioxetane 9) as well as the stability of alkyl-substituted 1,2-dioxetane derivatives 1 were investigated.

A decade ago, there was no clear explanation on the thermal decomposition mechanism of 1,2-dioxetanes. ${ }^{5}$ There were basically three mechanistic hypotheses: (i) a stepwise biradical mechanism, (ii) a merged (hybrid) mechanism where the $\mathrm{C}-\mathrm{C}$ bond elongates at the same time as the $\mathrm{O}-\mathrm{O}$ bond but breaks after and (iii) a concerted mechanism where both $\mathrm{O}-\mathrm{O}$ and $\mathrm{C}-\mathrm{C}$ bonds break concomitantly (Scheme 2). The rare attempts on mechanistic studies were only focusing on whether the $\mathrm{C}-\mathrm{C}$ and $\mathrm{O}-\mathrm{O}$ bonds were cleaved concertedly or in a stepwise process. At that moment, theoretical evidence showed the $\mathrm{C}-\mathrm{C}$ bond stretches along the reaction coordinate supporting a rather concerted, though not simultaneous, cleavage of both $\mathrm{C}-\mathrm{C}$ and $\mathrm{O}-\mathrm{O}$ bonds, the latter being more advanced than that of the $\mathrm{C}-\mathrm{C}$ bond. That would correspond more to a concerted biradical-like mechanism leading to two carbonyl derivatives.

Dark decomposition occurs if both carbonyl molecules are in the ground state, whereas chemiluminescence occurs after de-excitation if one of the carbonyls formed is excited in a singlet or triplet state. If the excited molecule is in the singlet state, it can either de-excitate rapidly to reach ground state or de-excitate through a close triplet state by an intersystem crossing (ISC) due to spin-orbit couplings (SOC), before reaching ground-state. In the first case, there will be a quick emission of light resulting in a fluorescence phenomenon and in the second case, there will be a longer emission of light coming with a phosphorescence phenomenon (Scheme 3).

Concerning the non-substituted 1,2-dioxetane 9, it had been experimentally observed that phosphorescence was favored over fluorescence by a factor of $1000 .^{6}$ In addition to the stability studies performed by Bastos and Baader, ${ }^{7}$ its decomposition has been analyzed through dynamic simulations and considering a stepwise mechanism involving biradical species obtained after torsion of the $\mathrm{O}-\mathrm{O}$ bond. What can be extracted from those studies is that the dynamics occurring during the reaction are complex. ${ }^{8}$ In particular, recent work reported by the group of Vacher and Lindh showed that the ground-state decomposition of 1,2-dioxetane is a fast process. ${ }^{9}$ The higher phosphorescence yield has been explained by the higher yield for formaldehyde in the triplet excited state compared to formaldehyde in the singlet excited state. Moreover, other theoretical calculations based on the computed cuts of potential energy surfaces 


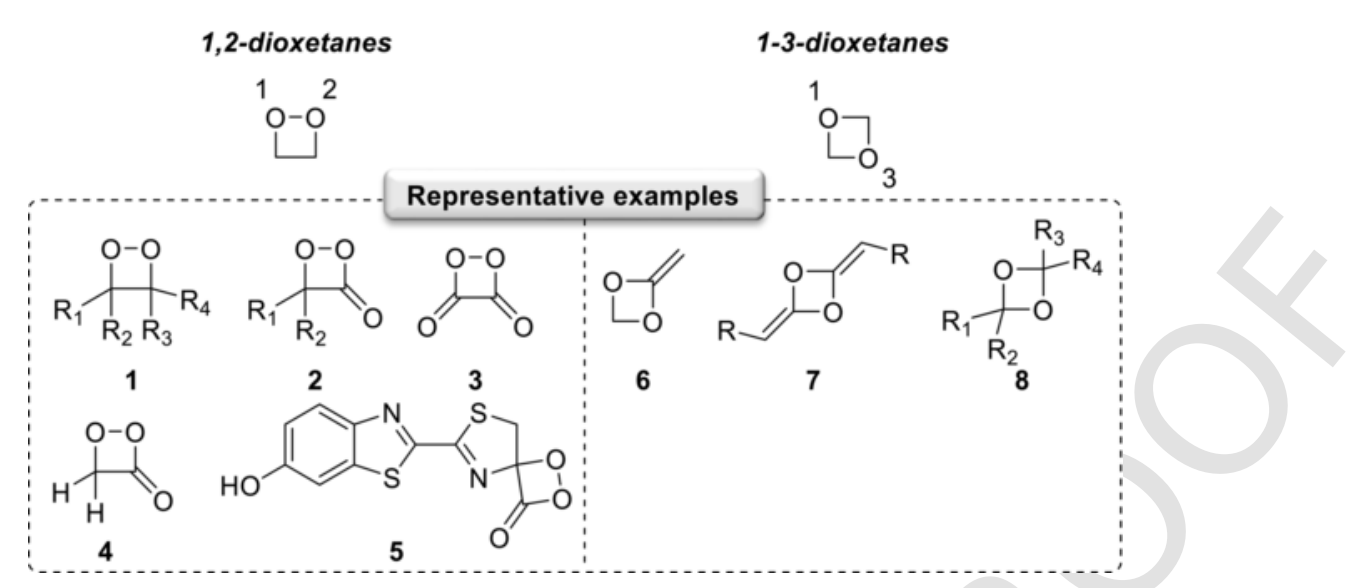

Scheme 1 Dioxetanes studied in the literature.

- stepwise biradical mechanism

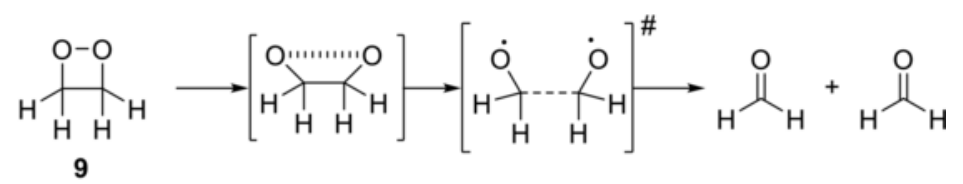

- merged mechanism

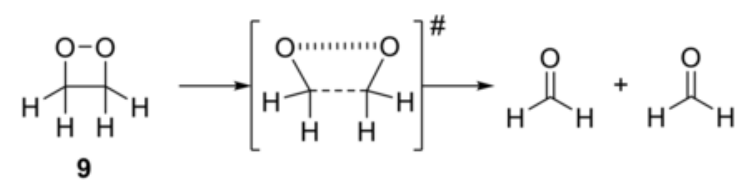

- concerted mechanism

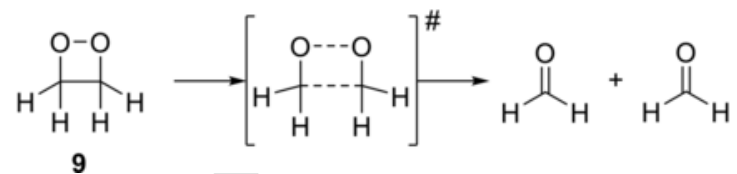

Scheme 2 Mechanistic hypotheses for the thermal decomposition of 1,2-dioxetane 9. Based on Farahani, P.; Roca-Sanjuán, D.; Zapata, F.; Lindh, R. J. Chem. Theory Comput. 2013, 9, 5404-5411.

$(\mathrm{PES})^{10}$ and calculations using the MultiState Complete Active Space Second-Order Perturbation Theory Coupled With a State-Averaged Complete Active Space Self-Consistent Field MS-CASPT2//CASSCF and MS-CASPT2//MS-CASPT2 methods were performed. ${ }^{11}$

The latter is showing that (i) the computed activation energy difference between 1,2-dioxetane 9 and transition state TS 9 (on Scheme 3) was $23.5 \mathrm{kcal} \mathrm{mol}^{-1}$ (experimental one being $22.7 \pm 0.8 \mathrm{kcal} \mathrm{mol}^{-1}$ ) and (ii) that after transition state TS 9, the nature of the vibrational mode most involved was guiding the molecule toward the formation of ground-state formaldehyde or toward $\mathrm{T}_{1}$ or $\mathrm{S}_{1}$ (respectively for triplet and singlet) potential energy surfaces (PES) after $\mathrm{C}-\mathrm{C}$ bond breaking. At this step of the mechanism, the calculated $\mathrm{T}_{1} \mathrm{PES}$ is lower in energy than $\mathrm{S}_{1}$ PES by approximately $5 \mathrm{kcal} \mathrm{mol}^{-1}$. Since along the potential energy surfaces there are regions of near degeneracy between $T_{1} / S_{1}$ and $S_{0}$, it is easier for a molecule on the $T_{1}$ PES than for a molecule on the $S_{1}$ PES to drop back to the singlet ground state. This energy difference, called "entropic trap," would then explain the major formation of the triplet excited state.

In addition, Vacher and Lindh reported that this "entropic trap" was determining the efficiency of the chemiluminescence of 1,2-dioxetane 9 and that very specific geometrical conditions $\left(\mathrm{O}-\mathrm{C}-\mathrm{C}-\mathrm{O}\right.$ dihedral angle lower than $55^{\circ}$ and $\mathrm{O}-\mathrm{C}-\mathrm{C}$ angles smaller than $117^{\circ}$ ) were necessary for the molecule's trajectories to escape the "entropic trap." "9 Another work reported by Roca-Sanjuán and Lindh ${ }^{12}$ reported that in addition to the conclusions reported by De Vico et al., ${ }^{11}$ the half-life time obtained for the entropic trap was $613 \mathrm{fs}$, which means that if a molecule has not on average transferred its population to the excited singlet or triplet state after that time, the molecule decomposes to ground state without light emission. Moreover, they calculated the energy difference between excited state $\mathrm{S}_{1} \mathrm{PES}$ and $\mathrm{T}_{1}$ PES being roughly 6-7 kcal mol ${ }^{-1}$, the triplet state being lower in energy as reported by De Vico, Liu et coll. 


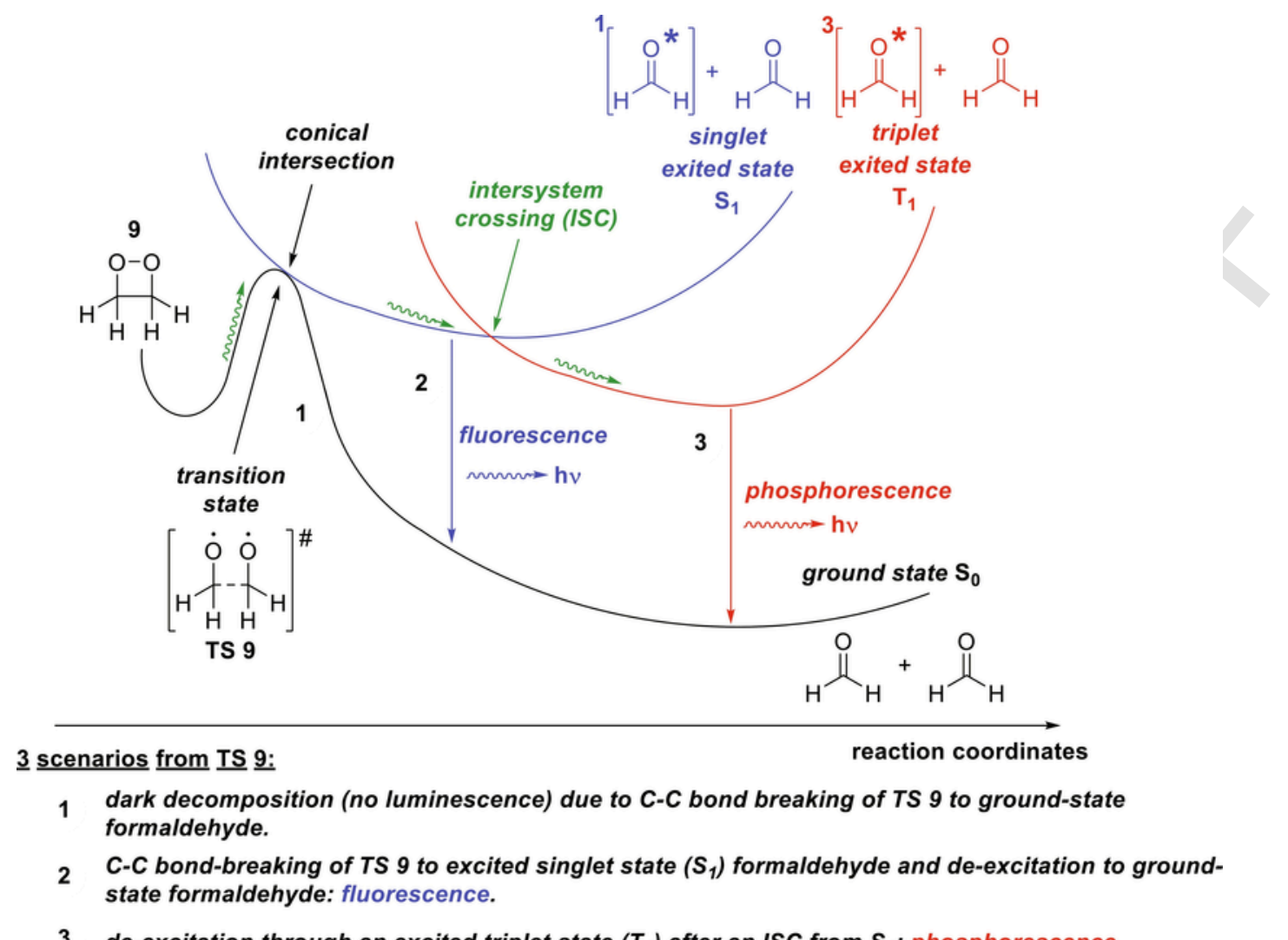

3 de-excitation through an excited triplet state $\left(T_{1}\right)$ after an ISC from $S_{1}$ : phosphorescence.

Scheme 3 Most probable mechanism and energetic diagram explaining the chemiluminescence phenomenon of 1,2-dioxetane 9.

In addition to those methods, the group of Ruedenberg recently set up a new theoretical analysis method helping to gain insight into the bonding between atoms in molecules through an analysis of $a b$ initio electron density matrices in terms of rigorous quasi-atomic orbitals (named QUAOS's). After developing it for wave functions (Hartree-Fock ${ }^{13}$ and strongly correlated ${ }^{14}$ ), they applied that analysis method to elucidate the bonding pattern of the urea molecule ${ }^{15}$ but also to elucidate the mechanism of 1,2-dioxetane dissociation into formaldehyde molecules. ${ }^{16}$ The results they obtained using their method were in accordance with all the previous calculations made in the study of the decomposition mechanism, i.e. that the breakage of both $\mathrm{C}-\mathrm{C}$ and $\mathrm{O}-\mathrm{O}$ bonds didn't occur in a concerted manner but in a two-stage process. They also could confirm the presence of a biradical structure.

2.1.1.2 Mechanistic studies on the decomposition of alkyl-substituted 1,2-dioxetane derivatives

Concerning alkyl-substituted 1,2-dioxetane derivatives, De Vico et al. supposed that it was possible that the relative energies of the first transition state with structure similar to that of TS 9 and their corresponding excited state products were different, leading to a possibly different mechanism. ${ }^{11}$

Some decades ago, the biradical-like mechanism was also used to rationalize both thermal stability of methyl-substituted 1,2-dioxetanes and singlet/triplet quantum yields. ${ }^{17}$ Stability of some of these molecules could be explained through orbital interactions obtained by determining the geometrical parameters with calculations. Moreover, trends in the quantum yields of chemiexcitation could be highlighted, showing that a concerted, almost simultaneous decomposition with no contribution of radicals was responsible for high excitation, whereas a biradical mechanism would result in the generation of mostly ground state carbonyl-derivatives, observed in the case of non-substituted 1,2-dioxetane.

Since then, some more studies were performed to evaluate the effect of alkyl-substituents on the stability of the corresponding 1,2-dioxetanes considering their chemiluminescent experimental properties.

$A b$ initio and hybrid DFT method calculations performed by the group of Baader in $2007^{7}$ showed that geometric parameters of alkyl-substituted 1,2-dioxetanes were in agreement with the experimental activation parameter data using a B3LYP/6-31G(d) level of calculation. Selecting the best calculation method was done by comparing the geometrical data of X-ray characterized alkyl-substituted 1,2-dioxetanes with computed ones using different methods. Investigation on 30 different structures revealed that (i) substitution does not have an impact on the $\mathrm{O}-\mathrm{O}$ bond distance; (ii) the mechanism hypothesized by Adam in the $1980 \mathrm{~s}^{17}$ is confirmed for the methyl-substituted 1,2-dioxetanes; (iii) the weaker $\mathrm{C}-\mathrm{C}$ bond in bulkier alkyl-substituted 1,2-dioxetanes is tending to a decomposition mechanism that is more synchronized ( $\mathrm{C}-\mathrm{C}$ and $\mathrm{O}-\mathrm{O}$ bonds are cleaved almost at the same time) and (iv) the shorter and thus stronger $\mathrm{C}-\mathrm{C}$ bond in 
less substituted 1,2-dioxetanes tips the scale in favor of a decomposition mechanism that is involving a biradical transition state. Comparing these data with experimental quantum yields shows that the hypothesis formulated by Adam 30 years ago on the methyl series, i.e., that chemiluminescence properties are related to the stability of the 1,2-dioxetanes, can be generalized to other alkyl-substituted 1,2-dioxetanes, although some exceptions exist. Quantitative models for the substituent influence on the 1,2-dioxetane stability have also been given in the same study. ${ }^{7}$

More recently, the group of Vacher and Lindh used kinetic models to explain why methyl-substituted 1,2-dioxetane derivatives of structure 1 were giving higher chemiluminescence yields. ${ }^{18}$ They found out that the decomposition was slower resulting in a bigger population transferred from the singlet ground-state of the transition state to the excited triplet state of the product resulting in a longer stay in the entropic trap region, thus a longer chemiluminescence event.

\subsubsection{Theoretical studies on the decomposition of 1,2-dioxetanones 2}

Most of the theoretical studies depicted in the following paragraphs concern either the work done for the elucidation of the mechanism of the degradation of simple 1,2-dioxetanone $\mathbf{4}$ or the work reporting studies on the mechanism of firefly dioxetanone $\mathbf{5}$ resulting in the bioluminescence phenomenon.

Besides, there have been several studies showing that 1,2-dioxetanes bearing an aromatic electron-donor moiety display an electron transfer or a charge-transfer induced decomposition, which generates light. These mechanisms have been named CIEEL for Chemically Initiated Electron-Exchange Luminescence and CTIL for Charge Transfer Induced Luminescence (Scheme 4). The readers are strongly advised to have a look at the literature published before 2008 to get more information about these mechanisms.

\subsubsection{Mechanistic studies on the decomposition of 1,2-dioxetanone and derivatives}

In order to understand the mechanism of decomposition of firefly 1,2-dioxetanone, several groups have been investigating the decomposition mechanism of simpler 1,2-dioxetanones as model compounds through theoretical calculations.

From an experimental point of view, there is not a lot of data regarding the decomposition of 1,2-dioxetanone 4. However, we do know that both singlet and triplet state products are formed with a large preference for triplet excited state products. ${ }^{19}$ Also, we know that the degradation of dimethyl-1,2-dioxetanone $\left(\mathrm{R}_{1}=\mathrm{R}_{2}=\mathrm{Me}\right.$ in the structure 2$)$ results in the generation of excited state singlet and triplet products, respectively, with quantum yields of $0.05-0.1 \%$ and $1.5 \%{ }^{20}$ Providing that the presence of methyl groups on the carbon atoms of the dioxetane and dioxetanone skeletons increases the efficiency of singlet and triplet excited state production, ${ }^{6}$ we can expect that the quantum yields for the formation of singlet and triplet state products of 1,2-dioxetanone 4 would be much lower, resulting in an increasingly inefficient chemiluminescence.

Until 2009, the mechanism of the thermal decomposition of 1,2-dioxetanone 4 was not fully known. Thanks to the development of new calculations methods, the group of Liu and Lindh succeeded in getting more information about the mechanism of the transformation. ${ }^{21}$ By using a MultiState Complete Active Space Second-order Perturbation Theory (MS-CASPT2) coupled with a State-Averaged Complete Active Space Self-Consistent Field (SA-CASSCF), they first calculated the activation energy of the transformation to be $26.0 \mathrm{kcal} \mathrm{mol}^{-1}$, which is superior to the one calculated for 1,2-dioxetane 7. This value seems logical because the $\mathrm{O}-\mathrm{O}$ bond is strengthened by the presence of the carbonyl function. Moreover, based on their calculations, they proposed a mechanism for the decomposition of 1,2-dioxetanone 4. They concluded that the decomposition takes place within the molecular plane, contrary to the case of 1,2-dioxetanes, and that there exist a particular biradical stage during the course of the reaction during which the potential energy surfaces of the ground and excited states are close in energy and intersect twice along the reaction path (ISCs on Scheme 5). This stage would be responsible for the formation of the excited-state intermediates explaining the chemiluminescence phenomenon.

However, this proposed mechanism has been contested by the group of Esteves da Silva because the previous work couldn't explain: (i) the inefficient chemiluminescence of 1,2-dioxetanone despite the crossings between $\mathrm{S}_{0}$ and $\mathrm{S}_{1} / \mathrm{T}_{1}$ PESs and (ii) why the excited triplet state was more populated than the singlet state despite a low energy difference between both energetic levels. ${ }^{22}$ They also decided to use

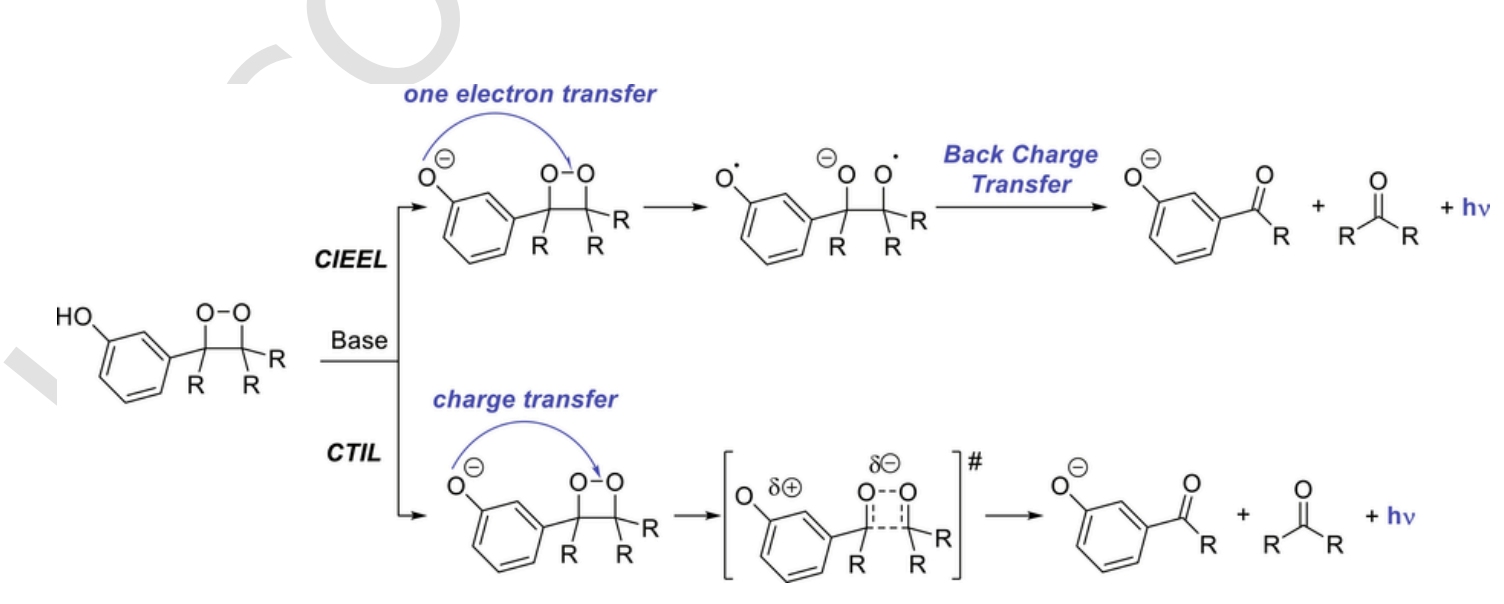

Scheme 4 CIEEL and CTIL mechanistic proposals. 


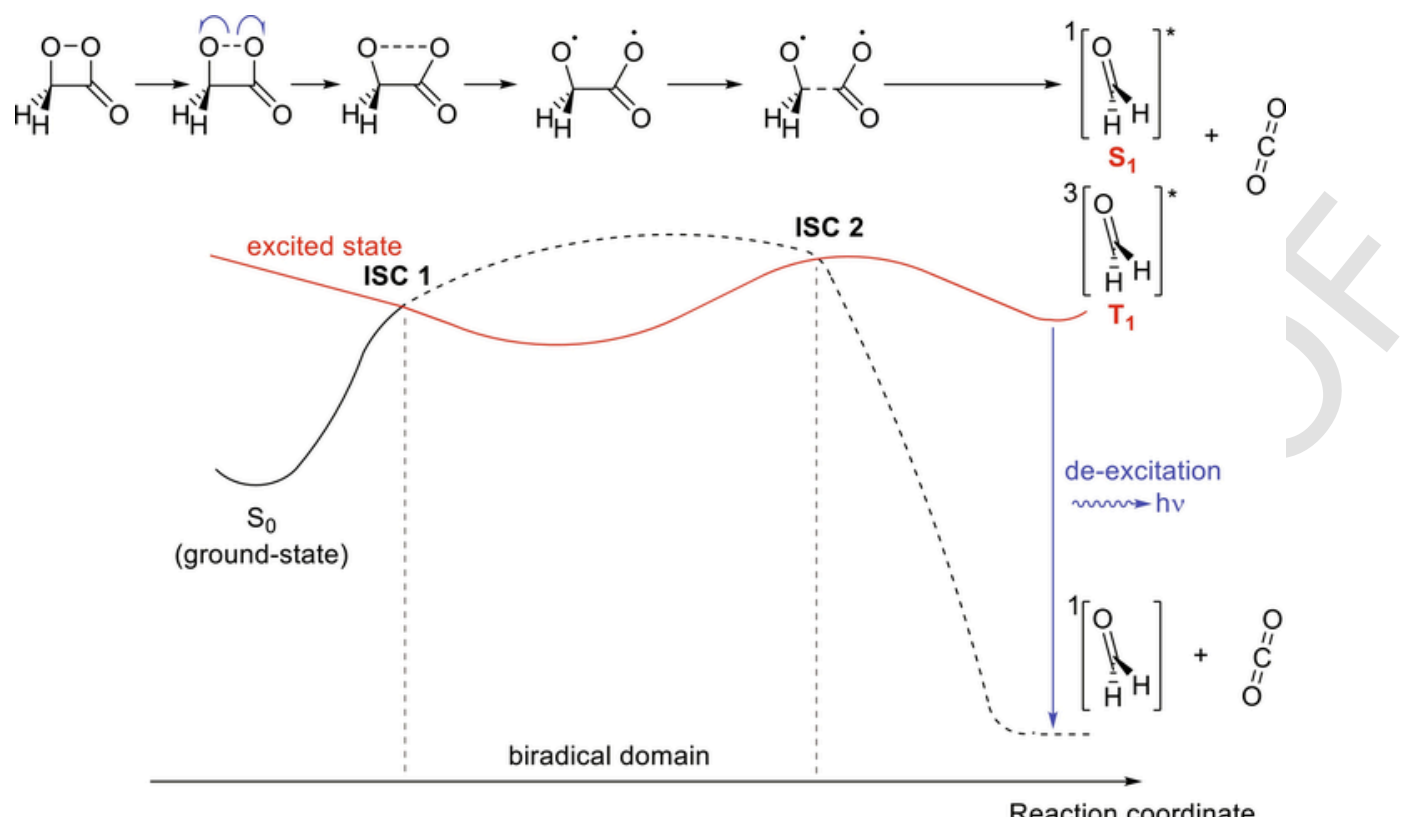

Scheme 5 Schematic description and energetic profile of the mechanism of the chemiluminescent decomposition. Based on Liu, F.; Liu, Y.; De Vico, L.; Lindh, R. J. Am. Chem. Soc. 2009, 131, 6181-6188.

higher levels of theory in their calculation method to check whether the reaction mechanism was going through a biradical intermediate as stated in the previous work.

The authors used a MPWB1K/aug-cc-pVDZ frequency analysis after a mPVKCIS/cc-pVDZ geometry optimization (closed-shell DFT methods) and concluded that the reaction mechanism was concerted rather than going through a biradical species. Besides, they could explain the inefficient chemiluminescence as consequence of a small triplet excitation yield due to an energy barrier in the $\mathrm{T}_{2} \mathrm{PES}$ after two intersections between the $\mathrm{S}_{1}$ PES and the $\mathrm{T}_{2} \mathrm{PES}{ }^{23}$ In addition, they also could explain the smaller singlet excitation thanks to the presence and absence of some intersystem crossing points between the singlet and triplet excited states. Furthermore, the authors could correlate their hypothesis by calculating the Mulliken atomic charges and comparing them to the one found for the decomposition of cyclobutane, which is known to be processing through a biradical intermediate. ${ }^{24}$ They concluded again that the mechanism was not going through a biradical species and proposed a dissymmetric dissociation of the $\mathrm{O}-\mathrm{O}$ bond which could also be explained by the dissymmetry of the molecule. They furthermore added that their results were in accordance with the experimental data.

The same year, the group of Lindh disputed the conclusions of Esteves da Silva et coll. ${ }^{23}$ as already two independent studies supported the mechanism involving a biradical intermediate. In order to understand why the energy difference found between the singlet and triplet excited states was superior to $14 \mathrm{kcal} \mathrm{mol}^{-1}$, they exploited the same calculation method as the one used by Esteves da Silva et al. ${ }^{22}$ They discovered that the transition state electronic structure has an open-shell character similar to the scenario found in the mechanism going through the biradical species. They stated that the results found by the group of Esteves da Silva were based on an incorrect ground state wave function generating larger errors in the calculation of the first singlet excited state $S_{1}$. In addition, they also questioned the presence of a large contribution of Hartree-Fock exchange, which is not appropriate for the calculation of the energies for singlet-triplet splittings.

The group of Esteves da Silva responded to that comment, ${ }^{25}$ reporting that their mechanism proposal was at least in accordance with the experimental results. Moreover, they explained that a biradical intermediate was unlikely to happen because of the polarity of the O-O bond due to the dissymmetry of the molecule. They also added that in the closed-shell singlet structure, electrostatic potential charges calculations were showing that the charge separation between the two oxygen atoms was increased, leading to a decreased biradical character of the transition state.

Later the same year, the groups of Liu and Lindh collaborated to question whether closed-shell DFT methods were appropriate to describe the thermolysis of 1,2-dioxetanone $4 .^{26}$ They re-evaluated the hypothesis of a concerted mechanism using closed-shell DFT methods including different Hartree-Fock exchange functionals. They concluded that the calculation of $\mathrm{S}_{0}$ with a large contribution of the Hartree-Fock exchange was not reliable because of the instability of the Kohn-Sham wave function used in the DFT method. They also stated that the appearance of double crossings between the $\mathrm{S}_{0}$ and $\mathrm{T}_{0}$ potential energy curves observed in the work of Esteves da Silva was actually an artifact. From their perspective, a concerted mechanism could not be considered.

Following those remarks, the group of Esteves da Silva revisited their study of the decomposition of 1,2-dioxetanone 4 to check whether the discovered computational artifacts have an impact on the results, and also to validate a closed-shell DFT method to study the chemiluminescence phenomenon. ${ }^{27}$ They decided to use three DFT functionals with different Hartree-Fock exchange and two different basis sets. As no particular energy difference between an open-shell approach and their closed-shell approach had been detected, they 
concluded that the use of a closed-shell method was appropriate to describe the chemiluminescence of 1,2-dioxetanone 4. Thanks to an analysis of the $\mathrm{S}_{0}$ Intrinsic Reaction Coordinate path, they confirmed their previously hypothesized concerted mechanism. However, they agreed with the comment made by Liu et al. about the presence of artifacts in their results, ${ }^{26}$ explaining them by the use of different geometric optimization methods. They plan, in a near future, to study the dynamics of the 1,2-dioxetanone decomposition and to evaluate the impact of the solvent in the reaction.

Even though the experimental results couldn't be explained with the biradical mechanism yet, the group of Lindh and Roca-Sanjuán investigated further in order to explain why there is a high triplet to singlet ratio. ${ }^{28}$ By studying the higher excited states $S_{2}$ and $T_{2}$ of the 1,2-dioxetanone molecule 4, they found out that, although $S_{2}$ energy level was not accessible, $T_{2}$ was sufficiently low in energy to be accessible in the biradical region (Scheme 6). Therefore, it means that there are two chemiexcitation paths $\left(\mathrm{T}_{1}\right.$ and $\left.\mathrm{T}_{2}\right)$ in the triplet manifold, whereas there is only one $\left(\mathrm{S}_{1}\right)$ in the singlet manifold. This would explain the higher triplet to singlet ratio in the chemiluminescence of 1,2-dioxetanone 4 . Those results were also correlated by spin-orbit coupling calculations.

Apart from 1,2-dioxetanone 4, decomposition of substituted 1,2-dioxetanone derivatives has been studied through theoretical calculations. The following paragraphs will be dealing with two types of substituted 1,2-dioxetanones, namely alkyl-substituted and thiazole-derived dioxetanones.

Although, experimental data are known for dimethyl-1,2-dioxetanone and mentioned for all studies regarding the decomposition of 1,2-dioxetanone 4, no theoretical study had been performed for the decomposition of dimethyl-1,2-dioxetanone. The group of Esteves da Silva calculated an activation energy for the decomposition of dimethyl-1,2-dioxetanone of $22.6 \mathrm{kcal} \mathrm{mol}^{-1}$ with zero-point corrections, ${ }^{29}$ which is in line with experimental values. ${ }^{19 c, 20 a, 30}$ They also concluded that triplet chemiexcitation yield may be explained by the presence of $S_{0}$ to $T_{1}$ and $T_{0}$ to $T_{1}$ intersystem crossings (ISCs), the last ISC explaining in particular the low chemiexcitation yield. Moreover, according to their results, it appears that charge-transfer processes are very important for ground-state decomposition. Therefore, they proposed a new mechanistic hypothesis called ICIC for Interstate Crossing-Induced Chemiexcitation to explain the difference found in the triplet/singlet ratio for various chemiluminescence products.

More recently, the chemiluminescent decomposition of spiro-adamantyl-1,2-dioxetanone has been investigated by the group of Farahani and Baader. ${ }^{31}$ Once prepared using reported procedures, ${ }^{32}$ a complete experimental study has been done for spiro-adamantyl-1,2-dioxetanone and it has been found that the singlet and triplet chemiexcitation yields were the same as dimethyl-1,2-dioxetanone, i.e. respectively $0.05-0.1 \%$ and $1.5 \%$. The activation energy for the decomposition of the spiro-adamantyl-1,2-dioxetanone was measured to be $28 \pm 2 \mathrm{kcal} \mathrm{mol}^{-1}$. The activation energy has also been evaluated through theoretical calculations and was found to be $28.7 \mathrm{kcal} \mathrm{mol}^{-1}$, which is in agreement with the experimental value. The theoretical calculations also show that (i) there is a common transition state in the rate-limiting step for ground and excited state product formation and (ii) for not rate-determining step ( $\mathrm{C}-\mathrm{C}$ bond cleavage), there are different energies for ground and excited state product formation. The calculations furthermore indicate the occurrence of a biradical mechanism for the decomposition of spiro-adamantyl-1,2-dioxetanone with preferential formation of triplet excited state products, which is in accordance with the triplet to singlet ratio measured.

In order to get closer to firefly dioxetanone, some studies on model compounds, i.e. thiazoline substituted 1,2-dioxetanone, have been performed. In 2009, the groups of Liu and Lindh used a state-average CASSCF (SA-CASSCF) geometry optimization and a multi-state

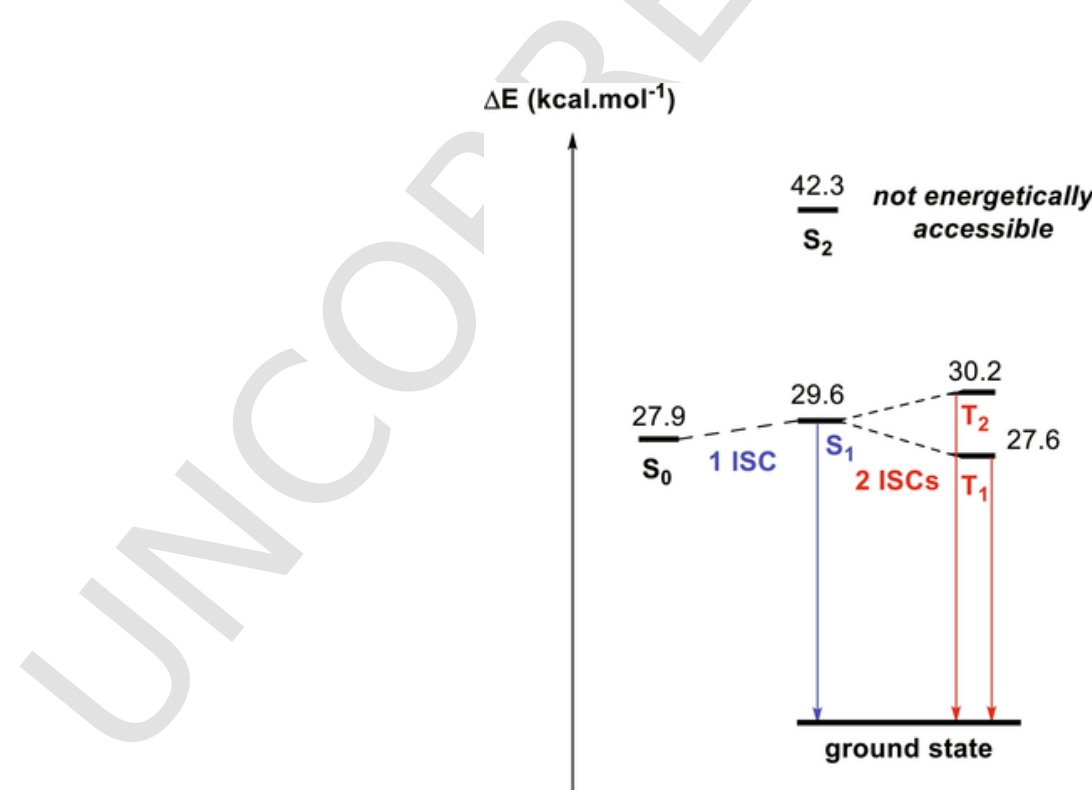

Scheme 6 Schematic energetic diagram for the decomposition of 1,2-dioxetanone. Energies at $\left(\mathrm{T}_{2}\right)_{\min }\left(\mathrm{T}_{2}\right.$ computed geometry from the structure of the transition state) relative to the energy of the TS are in kcal mol${ }^{-1}$. Data from Francés-Monerris, A.; Fernández-Galván, I.; Lindh, R.; Roca-Sanjuán, D. Theor. Chem. Acc. 2017, 136, article 70. 
CASPT2 (MS-CASPT2) calculation method to evaluate the influence of substituents on spiro-thiazoline derived 1,2-dioxetanones 10a-c (Scheme 7). ${ }^{33}$

It was found that neutral decomposition occurs for dioxetanones $\mathbf{1 0 a}$ and $\mathbf{1 0 b}$, which corresponds to a stepwise biradical mechanism like for 1,2-dioxetanes and 1,2-dioxetanones (considering that 1,2-dioxetanone decomposes through a biradical mechanism). Even though the authors didn't observe conical intersections between ground- and excited state PESs, they are close in energy around the biradical region, so there is a possibility of some adiabatic electron excitation processes. The authors also found out that no contribution of electron transfer excitation was implied in the neutral decomposition of dioxetanones 10a and 10b. Activation energies in the gas-phase have been calculated for those 1,2-dioxetanones and values of 31.7 and $32.9 \mathrm{kcal} \mathrm{mol}^{-1}$ were respectively found. Concerning 1,2-dioxetanone 10c, which corresponds to the deprotonated hydroxythiazoline-derived dioxetanone, the authors found out that the mechanism is rather concerted. The study of the nature of the concerted transition state supports a CTIL mechanism rather than a CIEEL mechanism. They calculated the energy barrier for the decomposition of $\mathbf{1 0 c}$ to be $24.9 \mathrm{kcal} \mathrm{mol}^{-1}$. However, no evidence was found that could explain the high chemiluminescence efficiency of this molecule.

A more recent study on thiazoline-substituted 1,2-dioxetanone decomposition has been published by the group of Esteves da Silva. ${ }^{34}$ To avoid any controversy between open-shell and closed-shell calculations, they decided to study closed-shell structures of six different 1,2-dioxetanones (including simple dioxetanone $\mathbf{4}$ and firefly dioxetanone 5) because it is commonly accepted that 1,2-dioxetanones are closed-shell molecules (Scheme 8).

Quantum theory of atoms in molecules (QTAIM) and topology of electron localization function (ELF) allowed -to discover that the $\mathrm{O}-\mathrm{O}$ bond is not covalent but has a charge-shifted character. They concluded that there was no possible homolytic cleavage of that bond, therefore no stepwise biradical mechanism could be highlighted. However, it was observed that the $\mathrm{C}-\mathrm{C}$ bond of the dioxetanone moiety in each molecule is covalent. Thus, the $\mathrm{C}-\mathrm{C}$ bond is stronger than the $\mathrm{O}-\mathrm{O}$ bond which is not in accordance with the fact that the rate-determining step of the decomposition mechanism is the $\mathrm{O}-\mathrm{O}$ bond cleavage as stated in other studies. ${ }^{6,21,22,25-27,29,35}$ They hypothesized that the rate-determining step should be the $\mathrm{C}-\mathrm{C}$ bond cleavage.

2.1.2.2 Mechanistic studies on the bioluminescent decomposition of firefly 1,2-dioxetanone and natural imidazopyrazinonederived 1,2-dioxetanones

Besides studying firefly dioxetanone model compounds, several groups have been interested in finding out the mechanism for the production and decomposition of the natural firefly dioxetanone in living organisms. From an experimental point of view, the quantum yield for the luminescence of firefly dioxetanone has been evaluated at $41 \%{ }^{36}$ and the light emitted from the Photinus pyralis luciferase is around $530 \mathrm{~nm}$, which corresponds to green light.

Up to 2008, the mechanism for the bioluminescence of fireflies was known, from a theoretical point of view, to involve D-luciferin, which was first phosphorylated by an ATP- $\mathrm{Mg}^{2+}$ molecule (Scheme 9). After deprotonation of the phenol moiety and the $\alpha$-position of the carboxylate, an oxygen molecule at the triplet excited state reacts with the formed carbanion and generates the anionic form of firefly

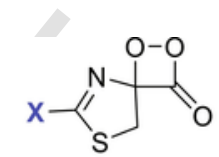

$$
\begin{aligned}
& X=H, H-T D O, 10 a \\
& X=O H, O H-T D O, 10 b \\
& X=O^{-}, O^{-}-T D O, 10 c
\end{aligned}
$$

Scheme 7 Thiazole-substituted dioxetanones studied by Liu et al. Based on Liu, F.; Liu, Y.; De Vico, L.; Lindh, R. Chem. Phys. Lett. 2009, 484, $69-75$.

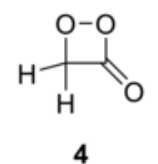

4

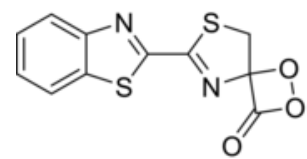

12<smiles>O=C1OOC12CSC=N2</smiles>

10a
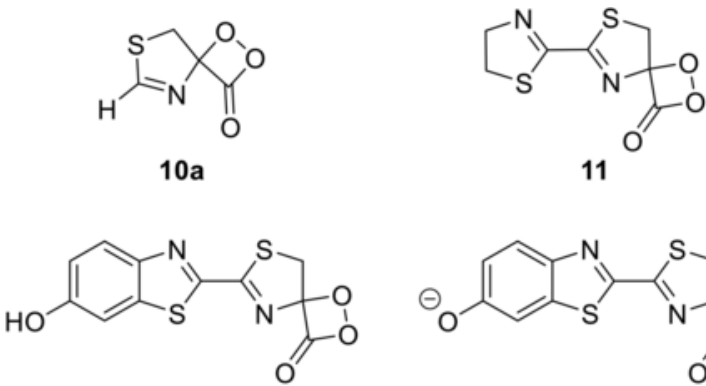

5<smiles>O=C1OOC12CSC(c1nc3ccc(O)cc3s1)=N2</smiles>

13

Scheme 8 1,2-Dioxetanones studied by Esteves da Silva et al. Data from Pinto da Silva, L.; Esteves da Silva, J. C. G. Struct. Chem. 2014, 25, 1075-1081. 


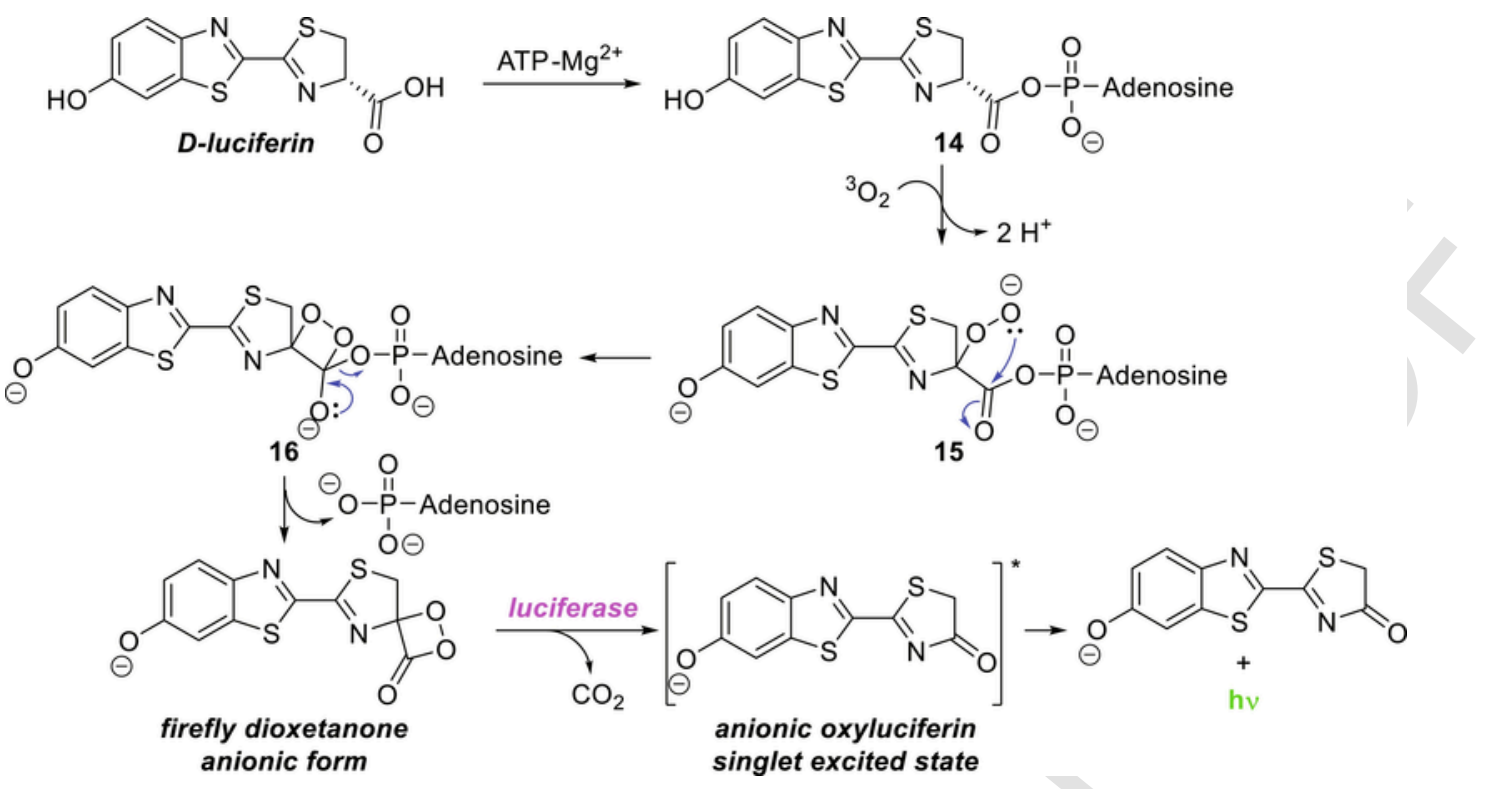

Scheme 9 Accepted general mechanism for the bioluminescence of fireflies. Based on Yue, L.; Liu, Y.-J.; Fang, W. H. J. Am. Chem. Soc. 2012, 134,11632 .

dioxetanone 5 through an intramolecular addition/elimination mechanism. Degradation of the anionic firefly dioxetanone into singlet excited state oxyluciferin is carried out inside the luciferase enzyme. Relaxation of the singlet excited oxyluciferin generates anionic ground state oxyluciferin and green light.

Inspired by the work made by the group of Mazziotti, showing that studies around firefly luciferin through active space calculation methods should require an active space larger than 28 electrons in 25 orbitals (variational calculation of a two-electron reduced density matrix-2-RDM) ${ }^{37}$ the groups of Ren and Goddard ${ }^{38}$ confirmed the hypothesis of a dioxetanone decomposition in luciferase through a stepwise biradical mechanism. ${ }^{39}$ Within their calculations, they considered the reaction to be performed in the gas phase and in a solvent using the polarized continuum model (PCM). Also, the hydrophobic environment of the enzyme has been simulated with diethylamine (dielectric constant of 3.58). Besides showing that the stepwise biradical mechanism is favored, they calculated the activation energies for the decomposition of firefly dioxetanone to be $7.4 \mathrm{kcal} \mathrm{mol}^{-1}$ in the gas phase and $8.4 \mathrm{kcal} \mathrm{mol}^{-1}$ with the PCM.

However, the protonation state of firefly dioxetanone inside the luciferase enzyme has been questioned by Liu et al. ${ }^{40}$ They considered both states in their CASPT2 and CAM-B3LYP calculation methods for investigations on the decomposition mechanism of firefly dioxetanone.

For the neutral form, they concluded that no charge transfer and back charge transfer occur during the decomposition. Therefore, the CIEEL and CTIL mechanisms are not viable for the reaction of firefly dioxetanone $\mathbf{5}$. They hypothesize that the chemiluminescent mechanism for the decomposition of the neutral firefly dioxetanone $\mathbf{5}$ occurs via an entropic trap.

For the anionic form of firefly dioxetanone, they found out that both charge transfer and back-charge transfer were gradual but no full one-electron charge transfer process was occurring. As there is no clear radical pair like in the intramolecular CIEEL mechanism, the latter cannot be considered. The authors postulated that the mechanism was more like a CTIL process but with gradual charge transfer and called it GRCTIL for Gradually Reversible Charge Transfer Initiated Luminescence. In addition, no conclusion had been reported about the protonation state of firefly dioxetanone in the luciferase enzyme.

Nevertheless, this question has been studied in more details a year later by the group of Esteves da Silva ${ }^{41}$ who studied the binding of intermediate 11 (see Scheme 9) to Luciola cruciata luciferase and the calculation indicated that the hydroxybenzothiazole moiety was protonated in the active site of the enzyme. ${ }^{42}$ The explanation relied also on the characteristics of luciferase enzymes, with a dielectric constant of 2.5-4 and a bioluminescence reaction $\mathrm{pH}$ of 5-8, whereas the firefly dioxetanone can be deprotonated only in water (dielectric constant of 78) and at basic $\mathrm{pH}$ between 7 and $10\left(\mathrm{p} K_{\mathrm{a}}\right.$ of the phenol moiety is around 9-10).

They performed excitation measurements by varying the $\mathrm{pH}$ of the solution but also calculations on six analogs of firefly luciferin with the mPWKCIS/6-31 + G(d,p) level of theory (Scheme 10).

The excitation measurements showed that the maximum light intensity was obtained at basic $\mathrm{pH}$ for each luciferin analog in water, which is consistent with the fact that the anionic form of firefly dioxetanone is a strong light emitter. The theoretical calculations showed that the hydroxybenzothiazole group of firefly dioxetanone possessed the same behavior as that of their analogs presented in Scheme $\mathbf{1 0}$. Given that the phenol moiety can only be deprotonated in polar environments (dielectric constant of 78 for water) and at basic $\mathrm{pH}$, and that bioluminescence occurs in hydrophobic environments in the luciferase (dielectric constant of 2.5-4) with a pH ranging between 5 and 8 , there is no possibility for the existence of the anionic form of firefly dioxetanone inside the active site of the luciferase enzyme. Moreover, this shows that the chemiexcitation must occur from the decomposition of the neutral form of firefly dioxetanone 5. They 
<smiles>O=C(O)[C@H]1CSC(c2nc3ccc(O)cc3s2)=N1</smiles>

D-luciferin<smiles>COc1ccc2nc(C3=NC(C(=O)O)CS3)sc2c1</smiles>

L-O-methylluciferin<smiles>O=C(O)[C@@H]1CSC(c2nc3ccc(O)cc3s2)=N1</smiles>

L-Iuciferin<smiles>CCOc1ccc2nc(C3=N[C@H](C(=O)O)CS3)sc2c1</smiles>

D-O-ethylluciferin<smiles>O=C(O)C1CSC(c2nc3ccc(O)cc3s2)=N1</smiles>

rac-luciferin<smiles>CC1(C)SC(c2nc3ccc(O)cc3s2)=N[C@@H]1C(=O)O</smiles>

D-dimethylluciferin

Scheme 10 Six analogs of firefly luciferin used in the study on the influence of the $\mathrm{pH}$ on the chemiluminescence made by Esteves da Silva et al. Based on Pinto da Silva, L.; Santos, A. J. M.; Esteves da Silva, J. C. G. J. Phys. Chem. A 2013, 117, 94-100.

hypothesized that the anionic form could be produced by an excited state proton transfer with an amino acid from the active site of the enzyme, which could be explained by the strong photoacidity of this type of molecules.

Besides getting more information about its thermal decomposition, the enzymatic mechanism underlying the synthesis of firefly dioxetanone has been the subject of a very recent study by the group of Navizet. ${ }^{43}$ They wanted to investigate how dioxygen was approaching luciferin and what is the mechanism for the formation of the dioxetanone ring. Two hypotheses have been proposed: (a) via the deprotonation of the $\alpha$-position of the carboxylate by the histidine 245 of the luciferase or (b) via the formation of a hydroperoxide radical (Scheme 11).

The authors first focused on path (a) which seemed to be the most reasonable. Their theoretical approach to check this hypothesis combines classical molecular dynamics, using an umbrella sampling simulation and hybrid QM/MM calculations. It was found that (i) dioxygen molecules can move freely inside the protein with no energetic barrier along the umbrella sampling simulation and (ii) when dioxygen approaches the deprotonated substrate, the electronic density shows a spontaneous electron transfer from the deprotonated intermediate to dioxygen, leading to the formation of a superoxide ion. Following is the final proposed mechanism resulting from the calculations made to elucidate the formation of the dioxetanone ring (Scheme 12). The readers should note that the protonation of the phenol moiety proposed by Esteves da Silva et al. ${ }^{41}$ hasn't been taken into account in this study and that potential future studies may complete the mechanistic proposal.

In addition to the studies performed about the decomposition of firefly dioxetanone, some others have been done on a bioluminescent phenomenon coming from marine organisms. Marine bioluminescence through decomposition of imidazopyrazinone-derived dioxetanones, used as a communication means between marine organisms (e.g., bacteria, planktons, coelenterates and crustaceans), is of interest for biotechnological and biomedical applications since there is no need for ATP- $\mathrm{Mg}^{2+}$ to produce the dioxetanone ring in vivo, contrary to firefly dioxetanone. The bioluminescence phenomenon of marine organisms has been mostly studied with two imidazo[1,2-a]-pyrazin-3(7H)-one (shortened imidazopyrazinone thereafter), which are vargulin (also called Cypridina luciferin) found in the ostracod Cypridina (Vargula) hilgendorfii and coelenterazine found in the jellyfish Aequorea Victoria (Scheme 13).

Experimental data are known for each dioxetanone-derived imidazopyrazinone: the bioluminescence quantum yield is $28 \%$ for vargulin ${ }^{44}$ and $20 \%$ for coelenterazine, ${ }^{45}$ both of them emitting blue light after thermal decomposition of the corresponding dioxetanones.

Former mechanistic studies on the decomposition of the imidazopyrazinone-derived dioxetanones showed rather a CTIL mechanism with polarization-induced branching excitation process (Scheme 14).

Within bioluminescence phenomena, the final excited product is in the singlet state, therefore a change in the spin-multiplicity is required during the course of the reaction as dioxygen, which is reacting, is in the triplet state. A lot of work has already been dedicated on the oxygen activation by enzymes. In addition to the activation of triplet-state dioxygen, there is another important problem associated with the spin transition, which is the intersystem crossing induced by spin-orbit coupling (SOC) for the thermal decomposition of cyclic peroxides. The group of Isobe performed a study to elucidate the influence of the protonation of the imidazopyrazinone substrates toward triplet oxygen and about the reactivity of the resulting dioxetanones. ${ }^{46}$ They found out that the protonation state was an important factor that was able to control the SOC in the thermolysis of the dioxetanones. On coelenterazine derivatives, the best protonation state for the CTIL mechanism is when the imidazopyrazinone possesses a deprotonated phenolic moiety.

The group of Roca-Sanjuán focused on the core structure of all those molecules, which is the imidazopyrazinone. ${ }^{47}$ They also wanted to know if the compounds were protonated or not inside the active site of the luciferase enzyme as it has been a controversy in several research papers. ${ }^{48}$ They decided to study small models of coelenteramide and Cypridina oxyluciferin, which result from the decomposition of the corresponding dioxetanones. 2-Acetamido-3-methylpyrazine in its neutral and anionic form $\mathbf{1 8}$ and $\mathbf{1 9}$ were chosen as model compounds (Scheme 15) and a CASSCF/CASPT2 calculation method was used to characterize their respective chemiluminescence and fluorescence.

The calculations showed that the anion was the relevant species for the efficient chemiluminescence of 2-acetamido-3-methypyrazine. However, the neutral species cannot be discarded because for other imidazopyrazinone derivatives, various functional groups can act as 
- (A) via deprotonation with the His 245 residue

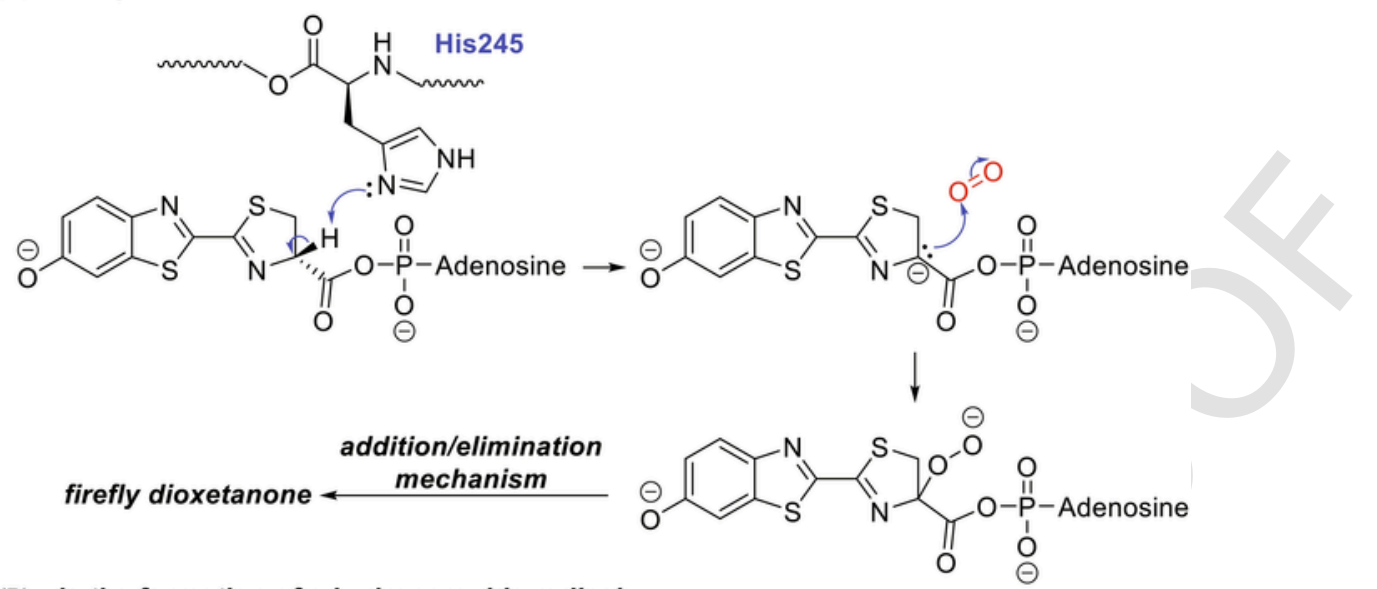

- (B) via the formation of a hydroperoxide radical

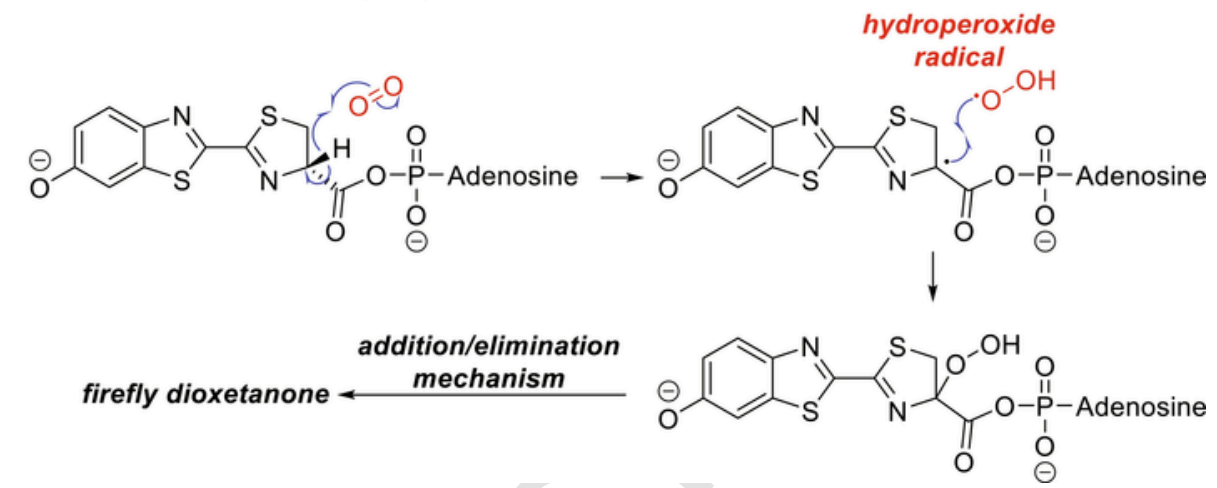

Scheme 11 Mechanistic hypotheses made by Navizet et al. for the formation of the firefly dioxetanone. Based on Berraud-Pache, R.; Lindh, R.; Navizet, I. J. Phys. Chem. B 2018, 122, 5173.

activators as proved in the literature. ${ }^{49}$ The protonation would depend on the closest amino acid in the luciferase enzyme and its capability to deprotonate the imidazopyrazinone derivatives.

Instead of studying numerous models, the group of Liu focused on Cypridina dioxetanone, which is coming from the oxidation of vargulin (Scheme 16). ${ }^{50}$

By using the Coulomb-attenuated hybrid-exchange correlation functional (CAM-B3LYP), which takes into account the charge transfer excitation energies, a detailed study of the thermolysis of neutral and deprotonated Cypridina dioxetanone has been performed. For neutral Cypridina dioxetanone, the authors identified a stepwise biradical mechanism with entropic trapping because of a low energetic barrier (calculated $20.9 \mathrm{kcal} \mathrm{mol}^{-1}$ and experimental around $20 \mathrm{kcal} \mathrm{mol}^{-1}$ ). In that case, the excited state products are coming from nonadiabatic transitions between the $\mathrm{S}_{0}$ and $\mathrm{S}_{1}$ states. For the anionic form, the authors suggested a rather asynchronous-concerted process with only one biradical transition state. In that case, the decomposition of anionic Cypridina dioxetanone includes a gradual charge transfer and a subsequent back charge transfer with the formation of excited products like for the other 1,2-dioxetanone derivatives, hence a GRCTIL mechanism is postulated. Overall, thermodynamically and according to the calculations, the anionic form of Cypridina dioxetanone is preferred over the neutral form in the case of Cypridina bioluminescence although the real emitter is neutral, meaning that the light emitter is protonated after the decomposition step at some point of the mechanism. Moreover, the authors demonstrated that the solvents had no effect on the decomposition of the neutral Cypridina dioxetanone, whereas it stabilized the charge transfer states thus enhancing the chemiexcitation in the case of anionic Cypridina dioxetanone.

Recently, the group of Esteves da Silva put in question all the revised CIEEL mechanisms (CIEEL, CTIL, GRCTIL) that have been proposed for the decomposition of imidazopyrazinone-derived dioxetanones because none of them were supported by experimental data. ${ }^{51}$ The previous mechanisms were stating that the anionic form generated anionic excited state products which were protonated before light emission. Studies made so far in basic solutions, where the dioxetanones (intermediate 17, Scheme 14) should be deprotonated, showed that negligible chemiluminescence yields were obtained. However, an appreciable quantum yield was measured in acidic solution, indicating that the neutral form is the light emitter. There is also another aspect, which hasn't been explained so far: the triplet to singlet ratio. Unfortunately, detecting experimentally the triplet state is very difficult. However, theoretical calculations could give an answer to those interrogations. Usually, in theoretical calculations, triplet states are ignored because it is known that bioluminescence is resulting from singlet excited state products. As postulated by Isobe et al., ${ }^{46}$ there is a possibility of singlet to triplet intersystem crossing depending 

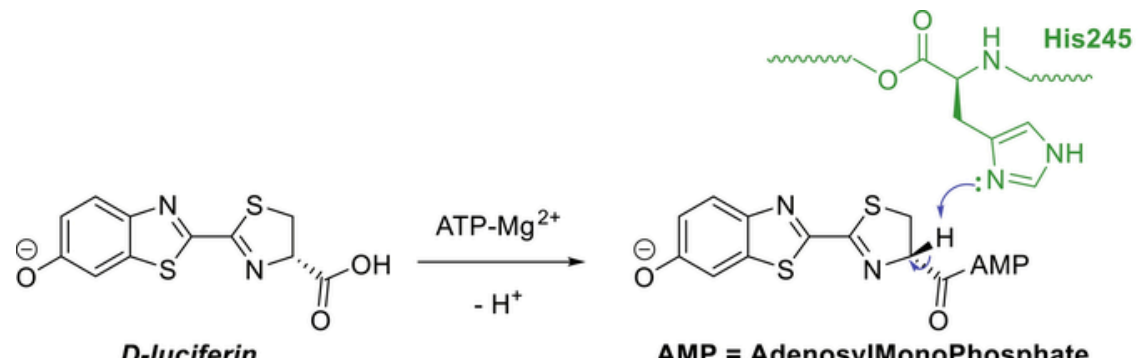

D-luciferin

AMP = AdenosyIMonoPhosphate

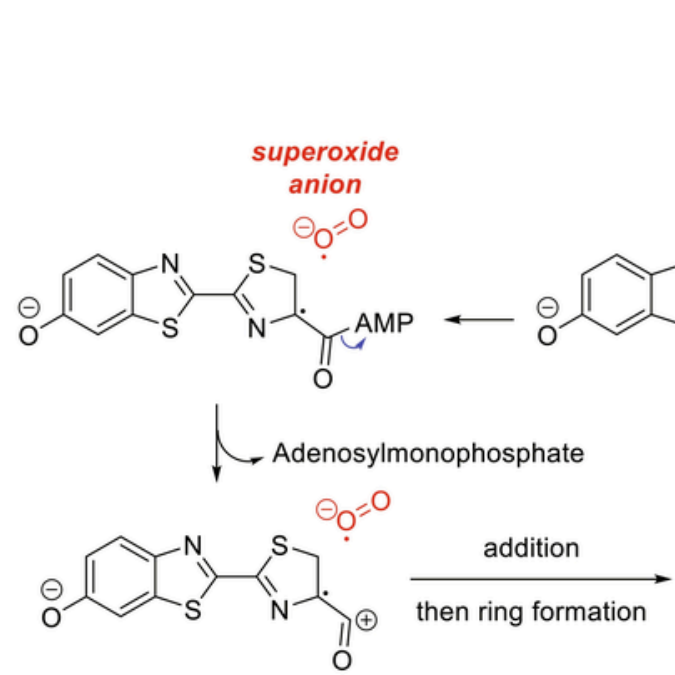

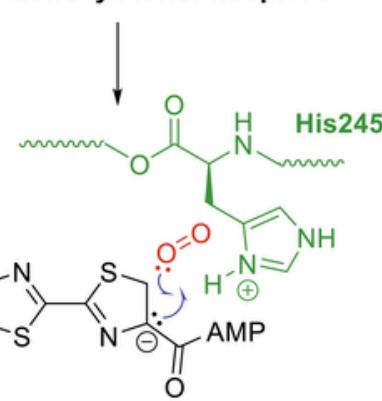

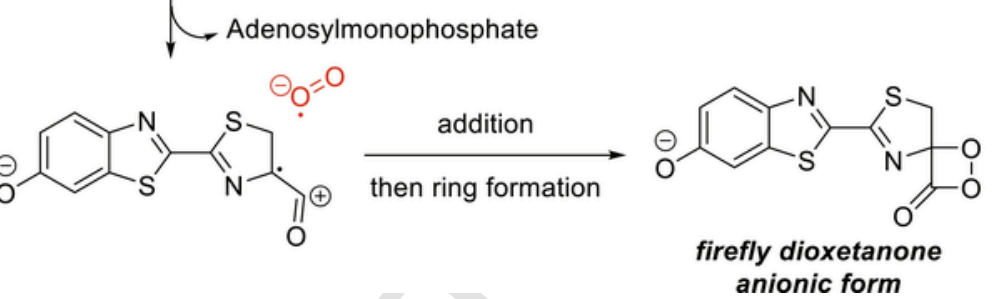

Scheme 12 Proposed mechanism for the formation of firefly dioxetanone in the active site of the luciferase. Based on Berraud-Pache, R.; Lindh, R.; Navizet, I. J. Phys. Chem. B 2018, 122, 5173.

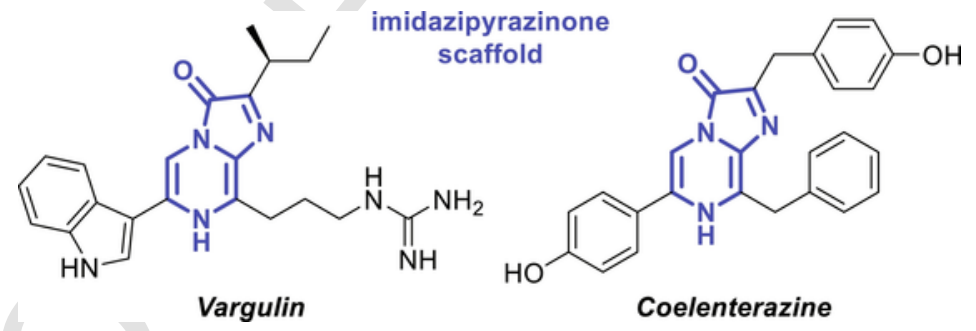

Scheme 13 Structures of the two main imidazopyrazinones studied in bioluminescence.

on the protonation state of the imidazopyrazinone-derived dioxetanones. According to their study, protonation increases the rate of intersystem crossing, whereas deprotonation suppresses it. However, the work made by Isobe and co-workers has been put into question because the B3LYP calculation method they used didn't take into account the charge transfer excitation energies. Thus, the group of Esteves da Silva hypothesized that in their previous studies, the group of Isobe drew a wrong conclusion on the protonation effect over the bioluminescence efficiency. They suggested that the efficiency of singlet chemiexcitation depends on the factors that govern intersystem crossing of cyclic peroxides. By using the $\omega$ B97XD functional in implicit diethylether and water, they discovered that the thermolysis of the imidazopyrazinone-derived dioxetanones proceeded via a stepwise biradical mechanism, consistent with what was previously reported. They also explained the $S_{0}$ to $S_{1}$ chemiexcitation by entropic trapping. However, the formation of the $S_{1}$ excited state products is not affected by the electron transfer step found for anionic imidazopyrazinone-derived dioxetanone as well as the charge transfer separation caused by polar solvents.

Another factor that governs the efficiency of light emission is the $S_{0}$ to $T_{1}$ intersystem crossing. The authors also found out that the inefficient chemi- and bioluminescence was not resulting from an inefficient chemiexcitation, but from a high triplet to singlet product ratio. The performed theoretical calculations are now supported by experimental findings. The group of Esteves da Silva concluded that 
<smiles>[R3]c1cn2c(=O)c([R])nc-2c([R])[nH]1</smiles><smiles>[R]c1cnc(NC2([R7])OOC2=O)c([R2])n1</smiles>

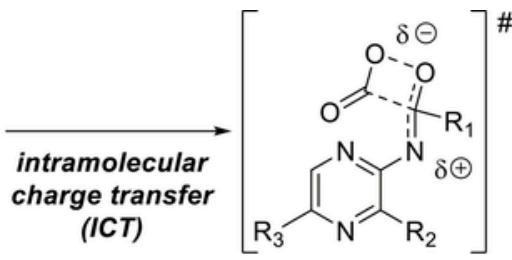

17 (ICT)

ICT transition state

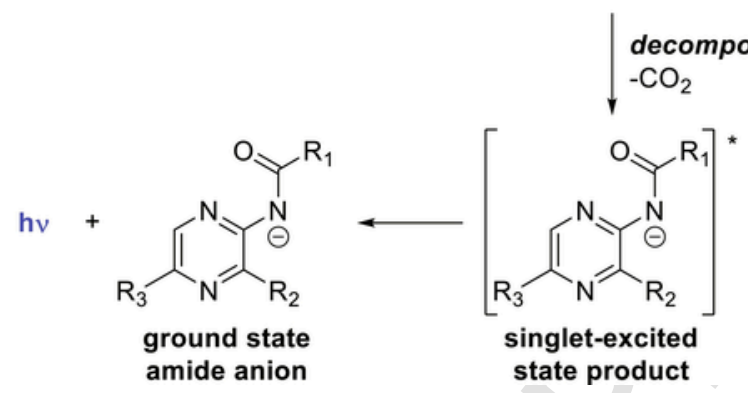

Scheme 14 Decomposition of imidazopyrazinone-derived dioxetanones through a CTIL mechanism. Based on Hirano, T.; Takahashi, Y.; Kondo, H.; Maki, S.; Kojima, S.; Ikeda, H.; Niwa, H. Photochem. Photobiol. Sci. 2008, 7, 197-207.<smiles>CC(=O)Nc1nccnc1C</smiles>

neutral form<smiles>CC(=O)Nc1nccnc1C</smiles>

anionic form

Scheme 15 2-Acetamido-3-methylpyrazine used in the study by Roca-Sanjuán et al. Based on Roca-Sanjuán, D.; Delcey, M. G.; Navizet, I.; Ferré, N.; Liu, Y.-J.; Lindh, R. J. Chem. Theory Comput. 2011, 7, 4060-4069.<smiles>CCC(C)c1nc2c(CCCNC(=N)N)[nH]c(-c3c[nH]c4ccccc34)cn-2c1=O</smiles>

Vargulin<smiles>CC[C@H](C)C1(Nc2ncc(-c3c[nH]c4ccccc34)nc2CCCNC(=N)N)OOC1=O</smiles>

Cypridina dioxetanone neutral form<smiles>CC[C@H](C)C1(Nc2ncc(-c3c[nH]c4ccccc34)nc2CCCNC(=N)N)OOC1=O</smiles>

Cypridina dioxetanone anionic form

Scheme 16 Formation of Cypridina dioxetanone from vargulin. 
neutral imidazopyrazinone-derived dioxetanones were responsible for efficient chemi- and bioluminescence, ${ }^{52}$ while anionic species present only negligible chemi- and bioluminescence. They proposed the same mechanism reported in their previous studies, ${ }^{29}$ i.e. an Intersystem Crossing-Induced Chemiexcitation (ICIC) mechanism, where electron and charge transfer are determining the activation barrier of the reaction.

\subsubsection{Theoretical studies on the decomposition of 1,2-dioxetanedione 3}

Even if 1,2-dioxetanedione has never been prepared as a stable compound, its presence in the peroxyoxalate chemiluminescence reaction has been detected by low temperature ${ }^{13} \mathrm{C}$ NMR studies $(\delta 154.8 \mathrm{ppm}) .{ }^{53}$ Moreover, its stability toward unimolecular dissociation at $298 \mathrm{~K}$ has been the subject of a recent study. ${ }^{54}$ Thanks to diverse calculation methods, the authors were able to evaluate the dissociation energy of 1,2-dioxetanedione using calculated crystal structure parameters that are given in Table 1 (calculations with the CCSD level).

Based on those values, the authors considered that during the dissociation process, the $\mathrm{O}-\mathrm{O}$ bond begins to break as its length is $2.100 \AA$ which reminisced them of a reported mechanism proposal where the formation of biradical species was formed to explain chemiluminescence. ${ }^{55}$ As no intrinsic reaction coordinate (IRC) calculation could be related to any stable $\mathrm{CO}_{2}$ dimer, the authors concluded that the dissociation was not thermally possible from compound $\mathbf{3}$ and as a consequence, this compound should be very stable toward unimolecular dissociation. This conclusion could also be confirmed by the calculated thermodynamic and kinetic parameters, where the dissociation barrier of compound 3 was evaluated at $119 \mathrm{~kJ} \mathrm{~mol}^{-1}$ and its half-life time at about $10^{6} \mathrm{~s}$ (around 12 days).

The group of Esteves da Silva independently reported a study on the unimolecular decomposition of 1,2-dioxetanedione 3 formed from oxalyl chloride and using a UCAM-B3LYP/6-31G(d,p) calculation method. ${ }^{56}$ In their conclusions, the authors stated that, contrary to the work described in the previous paragraph, the decomposition of dioxetanedione $\mathbf{3}$ was occurring through a stepwise biradical mechanism in line with their ICIC theory. ${ }^{29}$ Indeed, they calculated that after the transition state, the reaction proceeds toward the formation of excited products through limited intersystem crossings. These results revealed that there was degeneracy and near-degeneracy between the excited $\mathrm{S}_{1}, \mathrm{~S}_{2}, \mathrm{~T}_{1}$ and $\mathrm{T}_{2}$ states in the biradical domain, thus explaining the low efficiency of the chemiluminescence.

\subsection{Studies on 1,3-dioxetanes}

Almost no study has been reported on the chemistry of 1,3-dioxetanes because they have never been synthesized and therefore no data exist on those molecules. Nevertheless, a computational study has been done on four-membered cyclic ketene-X,X-acetals (X being O, NMe or $\mathrm{S}$ heteroatoms) and their corresponding cations (Scheme 17). ${ }^{57}$

Calculations with the MP2/cc-pvtz method indicated that 1,3-dioxetane 6 belongs to the $\mathrm{C}_{2 \mathrm{v}}$ symmetry group, whereas the cationic form 20 belongs to the $\mathrm{C}_{\mathrm{s}}$ symmetry group.

MP2 and DFT methods allowed the authors to evaluate the lengths of all bonds in molecules $\mathbf{6}$ and 20. Moreover, Mulliken charges have been calculated for 1,3-dioxetanone $\mathbf{6}$ and the cationic 1,3-dioxetanone 20. These results are summarized in Table 2.

Table 1 Calculated crystal structure parameters in the study of the unimolecular dissociation of 1,2-dioxetanedione.

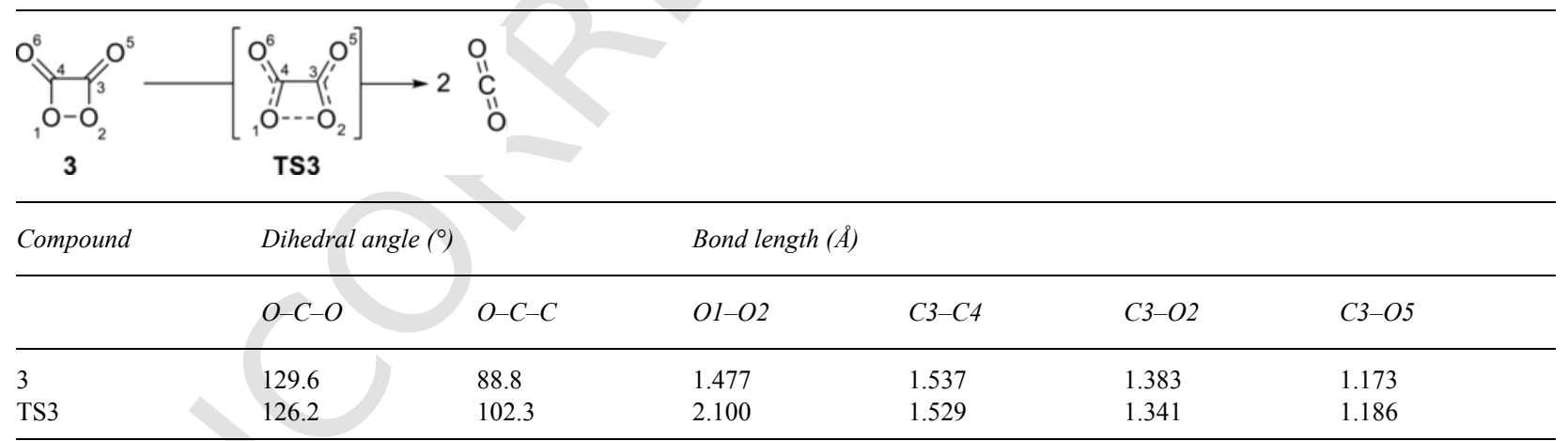

Data from Dunlap, B. I.; Schweigert, I. B.; Purdy, A. P.; Snow, A. W.; Hu, A. J. Chem. Phys. 2013, 138, article 134304.

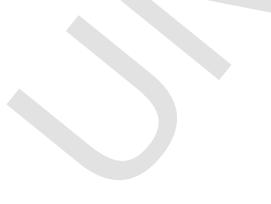

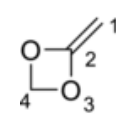

6

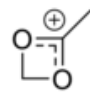

20

Scheme 17 1,3-Dioxetane derivatives present in the only reported computational study. Based on Beard, D. J.; Barakat, S. A.; Lockhart, N. B.; Pace, C. R.; Pittman Jr., C. U.; Hamil, B. W.; Saebo, S. Struct. Chem. 2012, 23, 351-357. 
Table 2 Calculated bond lengths using DFT and MP2 methods and Mulliken charges for 1,3-dioxetanes 6 and 20.

\begin{tabular}{lllllll}
\hline Compound & Bond length $(A)$ DFT/MP2 methods & & \multicolumn{2}{c}{ Mulliken charges (in au) } \\
\hline & $C 1-C 2$ & $C 2-O 3$ & O3-C4 & $C 1$ & $C 2$ & O3 \\
\hline 6 & $1.324 / 1.324$ & $1.382 / 1.377$ & $1.434 / 1.432$ & -0.49 & +0.39 & -0.32 \\
20 & $1.458 / 1.453$ & $1.305 / 1.300$ & $1.470 / 1.467$ & -0.22 & +0.46 & -0.18 \\
\hline
\end{tabular}

Data from Beard, D. J.; Barakat, S. A.; Lockhart, N. B.; Pace, C. R.; Pittman Jr., C. U.; Hamil, B. W.; Saebo, S. Struct. Chem. $2012,23,351-357$.

These results and especially the calculation of the Mulliken charges indicate that the 1,3-dioxetanone 6 would be a relatively good nucleophile.

\section{Experimental structural methods}

Plenty of new molecules containing the 1,2-dioxetane scaffold have been prepared these last years for the study of their properties in the frame of their applications in various domains. For this reason, the molecules described in the following sections will be restricted to natural products recently isolated and containing the 1,2-dioxetane scaffold. The selected isolated natural products are 5-hydroxy-4'-methoxy-8-prenyl-1",2"-peroxyl-3",3"-dimethyldihydropyrano[5,6:6,7]-isoflavone 5-hydroxy-4'-methoxy-6-prenyl-1"', $2^{\prime \prime \prime}$-peroxyl-3"', $3^{\prime \prime \prime}$-dimethyldihydropyrano[5,6:8,7]-isoflavone $\mathbf{2 2},{ }^{58}$ dendrofindlaphenol A $\mathbf{2 3},{ }^{59}$ 6 "-de- $O$-methyldendrofindlaphenol A $\mathbf{2 4},{ }^{59}$ dendronophenol A 25, ${ }^{60}$ dendronophenol B 26, ${ }^{60}$ ligulariaphytin A $27,{ }^{61}$ bidenphytin A $28,{ }^{62}$ bidenphytin B 29, ${ }^{62}$ neohupehenolide B 30, ${ }^{63}$ flavone derivatives 31 and $32,{ }^{64}$ cinnacassin I 33 and cinacassin J $34 .{ }^{65}$

The readers are also invited to consult the previous editions of the $\mathrm{CHC}$ collection to get more information on other compounds isolated. ${ }^{1,2}$

As no 1,3-dioxetane has been isolated up to now, no information about them will be provided.

\subsection{Spectroscopic methods}

\subsubsection{IR spectroscopy}

Infrared (IR) spectroscopy is not suitable for an absolute characterization of 1,2-dioxetanes specifically. The IR data provided in the publications related to the isolation of dioxetane-containing natural products concern other characteristic functional groups present in the molecular structures.

\subsubsection{NMR studies}

The newly isolated compounds have been characterized by ${ }^{1} \mathrm{H}$ and ${ }^{13} \mathrm{C}$ NMR spectroscopy. The following scheme shows the data for the 1,2-dioxetane moiety, with ${ }^{1} \mathrm{H}$ NMR chemical shifts depicted in blue and ${ }^{13} \mathrm{C}$ NMR chemical shifts in red (Scheme 18). Chemical shift values are given in ppm. Multiplicity is given as follows: singlet (s), doublet (d) and multiplet (m).

For compounds 21 and 22, the spectra were recorded in $\mathrm{CDCl}_{3}$ with a ${ }^{1} \mathrm{H}$ frequency of $300 \mathrm{MHz}$ and a ${ }^{13} \mathrm{C}$ frequency of $75 \mathrm{MHz}$. For compounds 23-27, the spectra were recorded in $\mathrm{CDCl}_{3}$, on a $400 \mathrm{MHz}$ spectrometer (frequency of $100 \mathrm{MHz}$ for the ${ }^{13} \mathrm{C}$ spectra). Compounds 28-32 were recorded on a $500 \mathrm{MHz}$ spectrometer (frequency of $125 \mathrm{MHz}$ for ${ }^{13} \mathrm{C}$ spectra) in $\mathrm{CDCl}_{3}$ for molecules $\mathbf{2 8}$ and $\mathbf{2 9}$, in $\mathrm{CD}_{3} \mathrm{OD}$ for products $\mathbf{3 0}$ and $\mathbf{3 1}$ and in DMSO- $\mathrm{d}^{6}$ for natural 1,2-dioxetane $\mathbf{3 2}$. Molecules $\mathbf{3 3}$ and $\mathbf{3 4}$ were recorded in $\mathrm{CD}_{3} \mathrm{OD}$ with a $600 \mathrm{MHz}$ spectrometer (with a frequency of $150 \mathrm{MHz}$ for ${ }^{13} \mathrm{C}$ spectra).

\subsubsection{UV-Vis spectroscopy}

The isolated 1,2-dioxetane-containing natural products were all obtained as colorless to diversely colored solids and UV spectroscopy has always been performed on those compounds. Table 3 gives data on the general aspect of the product as well as the wavelength of the maximum absorption (associated with the maximum molar extinction coefficient logarithm value $\log \varepsilon_{\max }$ ).

\subsubsection{Mass spectrometry}

The isolated natural 1,2-dioxetanes have been characterized also by HRMS, in comparison with the theoretical mass calculated from the molecular formula. For more information the reader should have a look at the experimental data given in the articles relevant to the isolation of the natural compounds $\mathbf{2 1 - 3 4} .^{58-65}$

\subsubsection{X-ray diffraction}

Although the natural 1,2-dioxetanes isolated are mostly solids, no crystal structure has been obtained. Concerning other dioxetane derivatives, due to the instability of most of them, only limited crystallographic data is available. ${ }^{1,2}$ In addition, estimations of the bond length and the dihedral angles have been performed using theoretical calculation methods (see Section 2). 


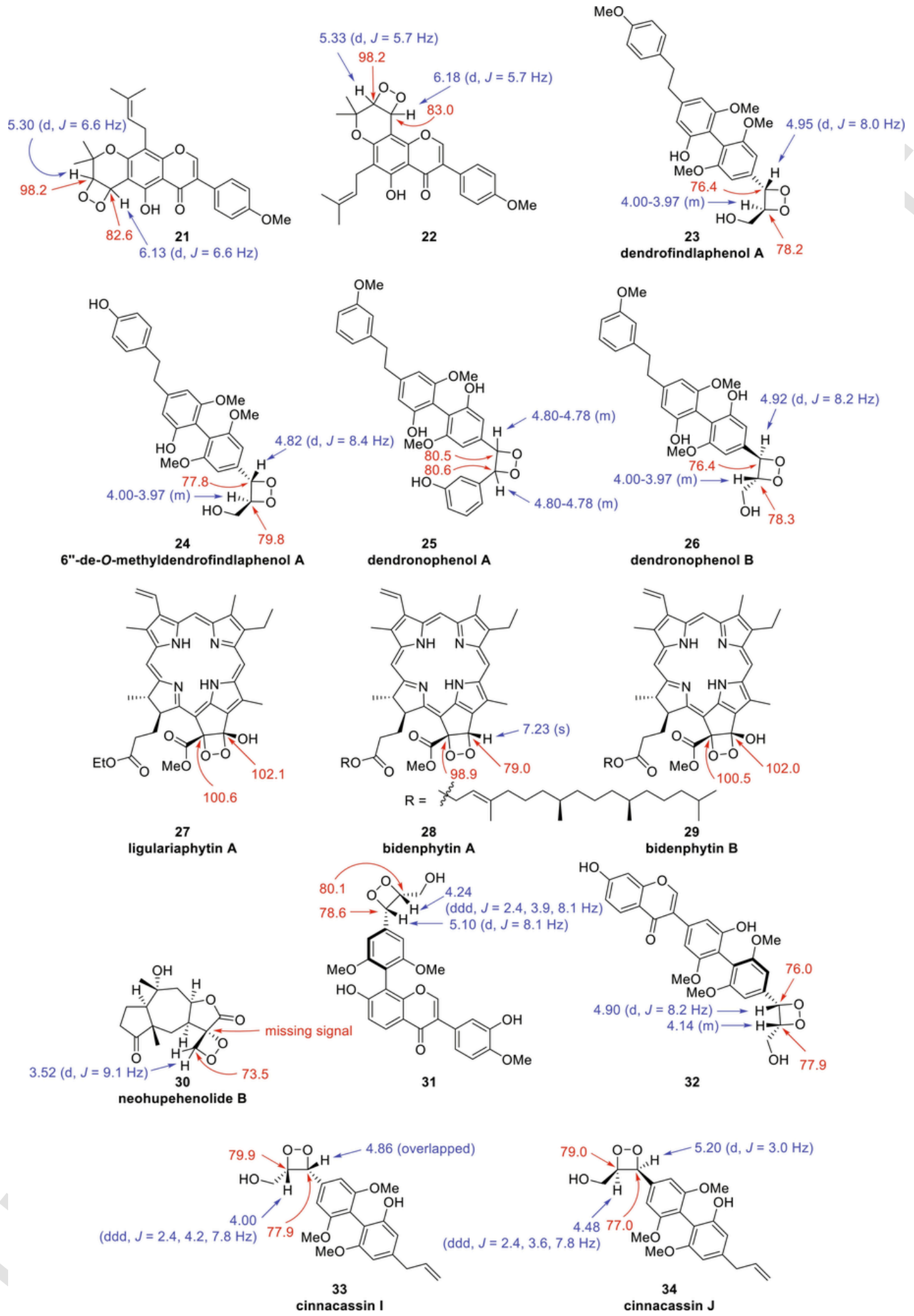




\subsubsection{Photoelectron spectra}

No new data is available for photoelectron spectroscopy of 1,2-dioxetane derivatives within the last decade. The readers are also invited to consult the second edition of the $\mathrm{CHC}$ collection to get values of ionization potentials for one compound. ${ }^{2}$

\subsection{Chemical methods}

The use of CHN microanalysis for the characterization of 1,2-dioxetanes is relatively rare, and HRMS analysis is preferred for its satisfactory level of accuracy. Like for other peroxides, iodometric titration can be used to determine the amount of oxygen content. Presence of oxygen in various solutions can now be detected using the chemiluminescence phenomenon of dioxetanes, making this family of chemicals suitable for chemical detection of several reagents.

\section{Thermodynamic aspects}

\subsection{Physical data}

No systematic tabulation of the melting points for solid 1,2-dioxetane derivatives exist. The values, when reported, can be found in the experimental section for the preparation of the corresponding 1,2-dioxetane derivatives.

Given the thermal sensitivity of 1,2-dioxetane derivatives, boiling points are not reported.

\subsection{Solubilities and chromatographic behavior}

1,2-Dioxetane derivatives behave the same way as most organic molecules regarding their solubility in various solvents and their chromatographic properties. No special precautions have to be taken while purifying stable 1,2-dioxetane derivatives, except that some of them may be thermally unstable. No specific problem has been reported regarding the solubility of 1,2-dioxetane derivatives, as it depends on their structure.

\subsection{Stability and thermochemical aspects}

Extensive tabulations on thermodynamic parameters (activation energy, enthalpies and entropies) are reported in the previous editions of the $\mathrm{CHC}$ collection for simple dioxetane derivatives as well as more complex and very stable derivatives. ${ }^{1,2}$ Some measured and calculated activation energies for the thermal dissociation of the dioxetane skeleton were reported in Section 2.

\section{Reactivity of dioxetanes}

No specific new reactivity of 1,2-dioxetane derivatives has been reported since 2008 as they are mostly prepared for their chemiluminescent properties by thermal degradation. The reactivity of 1,2-dioxetane derivatives has already been reported in the previous editions of the $\mathrm{CHC}$ collection and the reader is advised to read them to get the desired information. ${ }^{1-3}$

However, a new method for the degradation of 1,2-dioxetanes into excited carbonyl compounds has emerged. When the dioxetane scaffold is part of a specific polymer, it is possible to get chemiluminescence only by mechanically stretching the polymer chains and so without thermal activation. This phenomenon has been called mechanoluminescence and has been reported for the first time with 1,2-dioxetanes as the mechanophores by the group of Sijbesma in $2012 .{ }^{66}$ They incorporated a bis(adamantly)-1,2-dioxetane unit inside a polymer chain, which is able to emit blue light (at the wavelength of $420 \mathrm{~nm}$ ) when the dioxetane moiety is mechanically activated (Scheme 19).

In their study, using standard polymerization techniques, they prepared crosslinked polymer $\mathbf{3 5}$, linear polymer $\mathbf{3 6}$ and a polymer $\mathbf{3 7}$ possessing the adamantyl-1,2-dioxetane moiety at the end of the chain (Scheme 20). The mechanically activated chemiluminescence can be recorded directly from the singlet excited state adamantone polymer formed, but usually the emitted blue light is weak, which is the case of polymers $\mathbf{3 5}$ and $\mathbf{3 6}$. The chemiluminescence could also be harvested by energy transfer with a suitable acceptor.

Scheme 18 NMR data on the 1,2-dioxetane-containing natural products isolated within the last 12 years. Data from (a) Chen, S.-G.; Chen, J.-J.; Gao, K. Chem. Pharm. Bull. 2007, 55, 1181-1184. (b) Yang, D.; Cheng, Z.-Q.; Yang, L.; Hou, B.; Yang, J.; Li, X.-N.; Zi, C.-T.; Dong, F.-W.; Liu, Z.-H.; Zhou, J.; Ding, Z.-T.; Hu, J.-M. J. Nat. Prod. 2018, 81, 227. (c) Liu, Q.-F.; Chen, W.-L.; Tang, J.; Zhao, W.-M. Helv. Chim. Acta 2007, 90, 1745-1750. (d) Li, H.; Li, L.; Zheng, Q.; Kuroda, C.; Wang, Q. Molecules 2012, 17, 5219-5224. (e) Lee, T.-H.; Lu, C.-K.; Kuo, Y.-H.; Lo, J.-M.; Lee, C.-K. Helv. Chim. Acta 2008, 91, 79-84. (f) Ren, J.; Qin, J. J.; Cheng, X. R.; Yan, S. K.; Jin, H. Z.; Zhang, W. D. Arch. Pharm. Res. 2013, 36, 1319-1325. (g) Wen, R.; Lv, H.; Jiang, Y.; Tu, P. Bioorg. Med. Chem. Lett. 2018, 28, 1050-1055. (h) Liu, X.; Fu, J.; Yao, X.-J.; Yang, J.; Liu, L.; Xie, T.-G.; Jiang, P.-C.; Jiang, Z.-H.; Zhu, G.-Y. J. Nat. Prod. 2018, 81, 1333-1342. 
Table 3 UV-visible spectroscopic data for natural 1,2-dioxetanes 21-34.

\begin{tabular}{llll}
\hline Compound & Aspect & $\lambda_{\max }(\mathrm{nm})($ solvent $)$ & $\log \varepsilon_{\max }$ \\
\hline $\mathbf{2 1}$ & White amorphous solid & $267\left(\mathrm{CHCl}_{3}\right)$ & - \\
$\mathbf{2 2}$ & White amorphous solid & $269\left(\mathrm{CHCl}_{3}\right)$ & - \\
$\mathbf{2 3}$ & White amorphous powder & $209.2(\mathrm{MeOH})$ & 5.25 \\
$\mathbf{2 4}$ & White amorphous powder & $209.4(\mathrm{MeOH})$ & 5.12 \\
$\mathbf{2 5}$ & Gray powder & $201(\mathrm{MeOH})$ & 3.12 \\
$\mathbf{2 6}$ & Off-red amorphous powder & $208.5(\mathrm{MeOH})$ & 3.13 \\
$\mathbf{2 7}$ & Dark green amorphous powder & $402\left(\mathrm{CHCl}_{3}\right)$ & 3.35 \\
$\mathbf{2 8}$ & - & $404 / 505 / 534 / 612 / 669(\mathrm{MeOH})$ & - \\
$\mathbf{2 9}$ & - & $414 / 521 / 557 / 601 / 655(\mathrm{MeOH})$ & - \\
$\mathbf{3 0}$ & Colorless gum & $297(\mathrm{MeOH})$ & 8.00 \\
$\mathbf{3 1}$ & Light yellow amorphous powder & $205(\mathrm{MeOH})$ & 4.86 \\
$\mathbf{3 2}$ & Light yellow amorphous powder & $208(\mathrm{MeOH})$ & 4.61 \\
$\mathbf{3 3}$ & Yellow amorphous solid & $205(\mathrm{MeOH})$ & 3.81 \\
$\mathbf{3 4}$ & Yellow amorphous solid & $210(\mathrm{MeOH})$ & 3.75 \\
\hline
\end{tabular}

Data from (a) Chen, S.-G.; Chen, J.-J.; Gao, K. Chem. Pharm. Bull. 2007, 55, 1181-1184. (b) Yang, D.; Cheng, Z.-Q.; Yang, L.; Hou, B.; Yang, J.; Li, X.-N.; Zi, C.-T.; Dong, F.-W.; Liu, Z.-H.; Zhou, J.; Ding, Z.-T.; Hu, J.-M. J. Nat. Prod. 2018, 81, 227. (c) Liu, Q.-F.; Chen, W.-L.; Tang, J.; Zhao, W.-M. Helv. Chim. Acta 2007, 90, 1745-1750. (d) Li, H.; Li, L.; Zheng, Q.; Kuroda, C.; Wang, Q. Molecules 2012, 17, 5219-5224. (e) Lee, T.-H.; Lu, C.-K.; Kuo, Y.-H.; Lo, J.-M.; Lee, C.-K. Helv. Chim. Acta 2008, 91, 79-84. (f) Ren, J.; Qin, J. J.; Cheng, X. R.; Yan, S. K.; Jin, H. Z.; Zhang, W. D. Arch. Pharm. Res. 2013, 36, 1319-1325. (g) Wen, R.; Lv, H.; Jiang, Y.; Tu, P. Bioorg. Med. Chem. Lett. 2018, 28, 1050-1055. (h) Liu, X.; Fu, J.; Yao, X.-J.; Yang, J.; Liu, L.; Xie, T.-G.; Jiang, P.-C.; Jiang, Z.-H.; Zhu, G.-Y. J. Nat. Prod. 2018, 81, 1333-1342.

Indeed, while straining a film of polymer 36 that contained $0.5 \mathrm{wt} \%$ of an energy acceptor, the light emitted became stronger and also the color changed depending on the nature of the acceptor used. For example, blue light $(\lambda=440 \mathrm{~nm})$ was detected using 9,10-diphenylanthracene $\mathbf{3 8}$ as the acceptor, green light $(\lambda=510 \mathrm{~nm})$ was obtained using perylene 39, yellow light $(\lambda=590 \mathrm{~nm})$ was observed when using 4,7-di(thiophen-2-yl)benzo[c][1,2,5]thiadiazole $\mathbf{4 0}$ and red light $(\lambda=650 \mathrm{~nm})$ was detected when using $N, N^{\prime}$-bis(2,5-di-tert-butylphenyl)-3,4,9,10-perylene dicarboximide 41 (Scheme 21).

It also appeared that polymer $\mathbf{3 7}$ showed no observable luminescence, even in the presence of an energy acceptor, which would amplify the emission of the light produced. This result confirms the mechanical nature of the dioxetane decomposition process.

Two years later, the same group demonstrated that thermoplastic elastomers bearing the same bis(adamantyl)-1,2-dioxetane scaffold could also be prepared. ${ }^{67}$ Usually, the thermoplastic elastomers do not possess a lot of applications because of their tendency to degrade and their susceptibility to failure. Most of the time, investigation of the thermoplastic elastomer's failure mechanism is conducted by ESR, IR, XRD or NMR spectroscopy. ${ }^{68}$ Unfortunately, these methods lack sensitivity and resolution, rendering the investigation on the failure mechanism difficult.

Recent attention has been paid on the study of thermoplastic elastomers that can change color under mechanical force because of weak covalent ${ }^{69}$ or non-covalent bonds ${ }^{70}$ present in the macromolecular structures. The authors therefore thought that direct observation of chain scission events would help understanding their failure mechanism. They also used covalently bonded bis(adamantyl)-1,2-dioxetanes as a molecular probe for investigating failure in thermoplastic elastomers.

The study showed that when stretching the elastomer to failure, the intense mechanoluminescence observed was influenced by different parameters like the hydrogen bonding strength of the polymer chain with the matrix, the molecular weight of the polymer, the amount of mechanophore (bis(adamantyl)-1,2-dioxetane scaffolds) and the strain rate. In addition to that work, another study with silica-filled polydimethylsiloxane was conducted. ${ }^{71}$

Mechanoluminescence sensitivity could in addition be improved by addition of an energy acceptor inside the polymer chain. This has been demonstrated by incorporation of 9,10-bis(phenylethynyl)anthracene or 4,7-diphenylbenzo[c] [1,2,5]thiadiazole in a polyurethane chain. $^{72}$

\section{Preparation of dioxetanes derivatives}

The following subsections will be dealing with some methodologies for the preparation of 1,2-dioxetanes, 1,2-dioxetanones and the in situ preparation of 1,2-dioxetanedione, even if the latter one has never been isolated but evidence of its formation has been shown. 

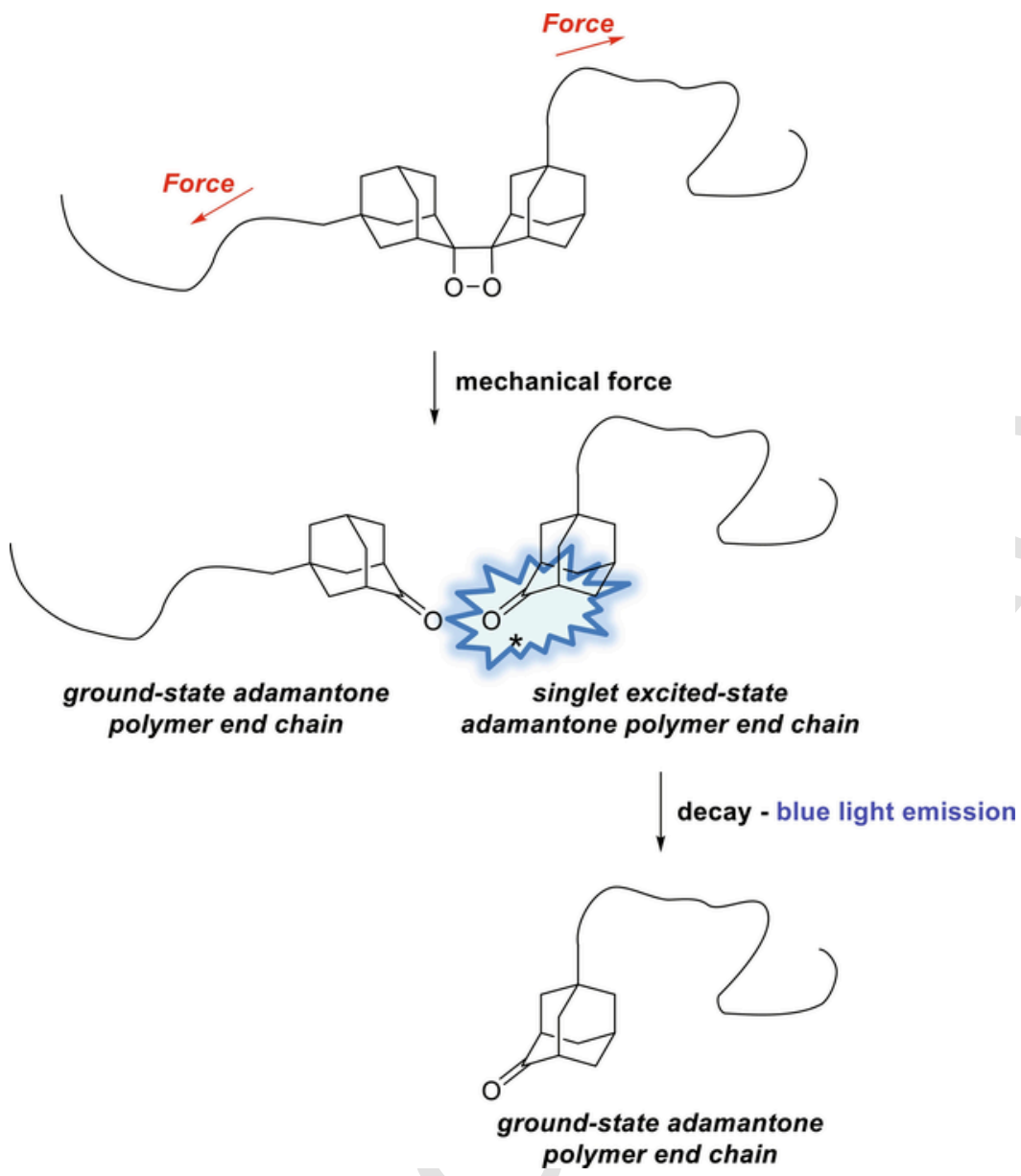

Scheme 19 General principle of the mechanoluminescence of 1,2-dioxetane-containing polymers. Based on Clough, J. M.; Creton, C.; Craig, S. L.; Sijbesma, R. P. Adv. Funct. Mater. 2016, 26, 9063-9074.

\subsection{Methods for the preparation of 1,2-dioxetane derivatives 1}

Plenty of methods exist for the efficient preparation of 1,2-dioxetanes. The following methods are the ones reported since 2008 but certainly there are others that have been described before. For an exhaustive list of methods on the synthesis of 1,2-dioxetanes, the reader is advised to consult the corresponding section in the previous editions of the $\mathrm{CHC}$ collection. ${ }^{1-3}$

\subsubsection{Synthesis of spirocyclobutyl-1,2-dioxetanes through a single electron transfer mechanism}

While searching for a way to prepare cyclopentanones by an oxidative ring-expansion of exomethylenecyclobutanes, the group of Yu discovered that stable spirocyclobutyl-1,2-dioxetanes could be efficiently prepared in the presence of cerium(IV) ammonium nitrate (CAN) and air. ${ }^{73}$ The following table is showing several examples of 1,2-dioxetanes that can be synthesized (Table 4). It appears that the reaction is particularly efficient with substrates bearing electron-rich aromatic rings (Table 4, entries 4-5). However, the scope of the reaction is not very broad since the alkene moiety cannot be fully substituted (Table 4, entries 6-7) and the transformation seems limited to the cyclobutane substrates, other cycloalkanes only providing complex mixtures.

The mechanism of the reaction begins with a single electron transfer promoted by CAN generating the radical cationic species $\mathbf{4 2}$ (Scheme 22). This radical intermediate reacts then with oxygen from the air forming radical peroxide $\mathbf{4 3}$ to give hydroperoxide $\mathbf{4 4}$, probably by radical $\mathrm{H}$ transfer with the solvent. The hydroperoxide $\mathbf{4 4}$ then cyclizes to generate the desired spirocyclobutyl-1,2-dioxetane with loss of a proton.

\subsubsection{Synthesis of 1,2-dioxetanes by [2+2]-cycloaddition with molecular oxygen}

The $[2+2]$-cycloaddition of singlet oxygen with electron-rich alkenes is probably the most used method for preparing 1,2-dioxetanes because it is convenient and versatile. The method itself is not new and has already been reported in the corresponding chapter of the 
- preparation of the crosslinked polymer 35

n<smiles>C=CC(=O)OCCOC12CC3CC(C1)CC(C14CC5CC(C1)C(OCCOC(=O)C=C)(C5)C4)(C3)O2</smiles><smiles>[3H]CC</smiles><smiles>CCC(C)C(=O)OCCOC12CC3CC(C1)C(C14CC5CC(C1)C(OCCOC(=O)C(C)CC)(C5)C4)C3O2</smiles>

- preparation of the linear polymer 36

n

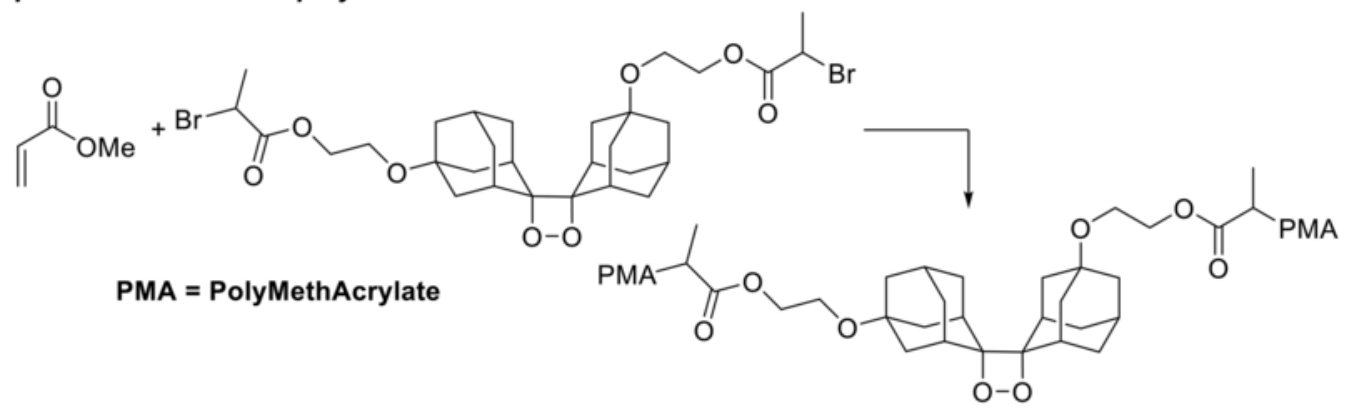

36

- structure of polymer 37 possessing the 1,2-dioxetane moiety at the end chain<smiles></smiles>

37

Scheme 20 Preparation of different polymers possessing the bis(adamantyl)-1,2-dioxetane scaffold. Based on Chen, Y.; Spiering, A. J. H.; Karthikeyan, S.; Peters, G. W. M.; Meijer, E. W.; Sijbesma, R. P. Nat. Chem. 2012, 4, 559-562.

previous editions within the $\mathrm{CHC}$ collection. ${ }^{1-3}$ The following table gives an overview of some 1,2-dioxetanes prepared with this method since 2008 (Table 5).

\subsubsection{Synthesis of 1,2-dioxetanes by action of sodium hydride on diols}

A single example for the preparation of 1,2-dioxetane derivatives from diols in the presence of sodium hydride has been reported by the group of Huq in $2014 .^{86}$ The diol substrate is first deprotonated with sodium hydride, generating a dianion that can undergo a retro-addition reaction to give phenanthrene-9,10-dione (Scheme 23). The dianion can also engage in a $(3,3)$ rearrangement providing the bis-enolate 46. In the presence of phenanthrene-9,10-dione, intermediate $\mathbf{4 6}$ can be transformed into the biradical species $\mathbf{4 7}$, which can cyclize via a $[2+2]$-cycloaddition to give biradical 48. After an oxidation step generating biradical $\mathbf{4 9}$, a retro-Diels-Alder reaction provides the biradical intermediate 50. Both radicals recombine then to give the desired 1,2-dioxetane $\mathbf{4 5}$ in $75 \%$ yield.

\subsubsection{Synthesis of 1,2-dioxetanes in the presence of a platinum-hydroperoxide complex}

Only one example has been reported for the use of an hydroperoxo-hydroxo platinum(IV) complex for the preparation of a 1,2-dioxetane derivative. ${ }^{87}$ By reaction of this new complex with tetramethylethylene, the corresponding tetrasubstituted 1,2-dioxetane could be isolated with $15 \%$ yield (Scheme 24). 
<smiles>c1ccc(-c2c3ccccc3c(-c3ccccc3)c3ccccc23)cc1</smiles>

38

blue light $(440 \mathrm{~nm})$

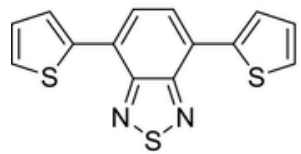

40

yellow light $(\mathbf{5 9 0} \mathbf{~} \mathbf{m})$

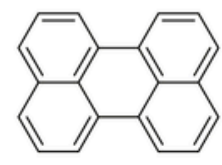

39

green light $(\mathbf{5 1 0} \mathbf{~ n m})$

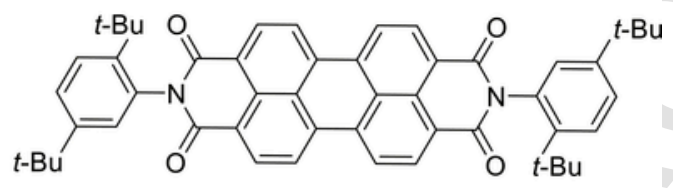

41

red light $(650 \mathrm{~nm})$

Scheme 21 Energy acceptors evaluated for the mechanoluminescence of bis(adamantyl)-1,2-dioxetane polymers. Based on Chen, Y.; Spiering, A. J. H.; Karthikeyan, S.; Peters, G. W. M.; Meijer, E. W.; Sijbesma, R. P. Nat. Chem. 2012, 4, 559-562.

Table 4 Synthesis of spirocyclobutyl-1,2-dioxetanes with CAN and air.

\begin{tabular}{lll}
\hline \\
Entry
\end{tabular}

Data from Yu, L.; Ren, L.; Yi, R.; Guo, R. Synth. Commun. 2011, 41, 2530-2538.

6.1.5 Synthesis of 1,2-dioxetanones by oxidation with Oxone ${ }^{\circledR}$ and Shi's catalyst

In Shi's epoxidation conditions, the group of Krawczyk demonstrated that 1,2-dioxetanes could be obtained as an isolable byproduct. ${ }^{88}$ Mixing Shi's catalyst and Oxone ${ }^{\circledR}$ generates a chiral dioxirane that can react with an alkene function to provide an epoxide. ${ }^{89}$ Although this stereoselective epoxidation method has already been known for a long time, the generation of 1,2-dioxetane byproducts is relatively scarce. In the example below, 1,2-dioxetane derivative $\mathbf{5 2}$ has been obtained in a mixture with epoxide $\mathbf{5 1}$ and $25 \%$ yield (Scheme $\mathbf{2 5}$ ). 


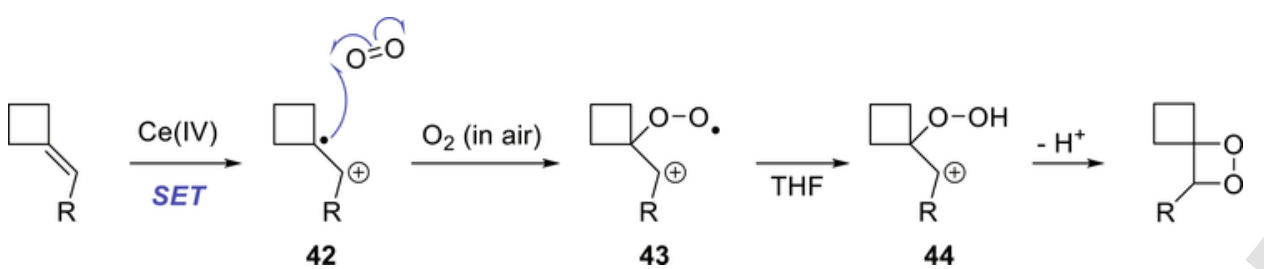

Scheme 22 Postulated mechanism for the formation of spirocyclobutyl-1,2-dioxetanes with CAN and air. Based on Yu, L.; Ren, L.; Yi, R.; Guo, R. Synth. Commun. 2011, 41, 2530-2538.

\subsection{Methods for the preparation of 1,2-dioxetanone derivatives 2}

A couple of methods for the preparation of 1,2-dioxetanone derivatives 2 will be reported in the following subsections. One of them has already been described in the previous editions of the $\mathrm{CHC}$ collection and an update will be made in that case.

\subsubsection{Synthesis of 1,2-dioxetanones in the presence of ozone and triphenylphosphite}

When ozone and triphenylphosphite are mixed together, triphenylphosphite ozonide 53, which is a precursor of singlet oxygen, is formed. Then, the reaction mechanism involved is the same as the [2+2]-cycloaddition of alkenes. Hereafter is an example for the use of this method that has been reported in 2009 by the group of Romieu and Renard (Scheme 26). ${ }^{90}$

\subsubsection{Synthesis of 1,2-dioxetanones by cyclization of $\alpha$-peroxyacids in the presence of DCC}

Another method for the preparation of 1,2-dioxetanones, which had already been reported in the previous editions of the CHC collection, consists in the lactonization of $\alpha$-peroxycarboxylic acids in the presence of dicyclohexylcarbodiimide (DCC). The mechanism of the lactonization is the same as the Steglich esterification. ${ }^{91}$ This method has been used in 2012 by the group of Baader to prepare 1,2-dioxetanone derivatives 54, 55 and $\mathbf{5 6}$ in 5\%, 55\% and 1\% yield, respectively (Scheme 27). ${ }^{32}$ The low yields for $\mathbf{5 4}$ and $\mathbf{5 6}$ were due do the instability of the dioxetanones prepared. Indeed, they could only be isolated as solutions in dichloromethane after cold distillation and the solutions had to be stored at $-80^{\circ} \mathrm{C}$ to avoid any degradation.

\subsection{Method for the in situ preparation of 1,2-dioxetanedione 3}

As specified in the peroxyoxalate chemiluminescence studies, 1,2-dioxetanedione $\mathbf{3}$ has to be prepared in situ just before its decomposition and energy transfer to convenient acceptors. Usually, these studies are made for bioassays especially to detect the presence of specific compounds like biomarkers, ${ }^{92}$ glucose in human serum ${ }^{93}$ or alkaline phosphatase in milk. ${ }^{94}$

Typically, for those studies, 1,2-dioxetanedione is prepared from 2,4,6-trichlorophenyloxalate and imidazole following the path shown in Scheme 28. ${ }^{92-95}$

\section{Important compounds and applications}

The following sections will give some information on current applications of dioxetane derivatives. Since their applications were not developed a lot in the previous CHC volumes, ${ }^{1-3}$ an overview on the reported applications will be described. Given the large number of reports, only the major applications will be developed. For more information, the readers are invited to consult the respective references.

\subsection{Medicinal chemistry}

Natural peroxides like artemisinin 57, extracted from the Chinese herb Artemisia annua, are known to possess antimalarial activities. The mechanism of action of these peroxidic drugs is still controversial but it seems that an iron-catalyzed Fenton reaction takes place when the parasite invades the red blood cells. ${ }^{96}$ Artemisinin is mostly obtained from natural resources because its synthesis from commercially available reagents is too costly and relatively complex. However, its natural availability is erratic, which is why access to other simpler peroxidic drugs possessing antimalarial activities is needed.

Recently, the group of Ciscato reported on the preparation and in vitro biological tests of five 1,2-dioxetane derivatives on Plasmodium falciparum cell cultures. Results of the biological tests for 1,2-dioxetanes $\mathbf{5 8}, \mathbf{5 9}, \mathbf{6 0},{ }^{97} \mathbf{6 1}$ and $\mathbf{6 2}{ }^{98}$ are reported in Table 6.

These results made the authors state that all the 1,2-dioxetane derivatives tested possess significant antiplasmodial activities and that they all were as efficient as artemisinin. 
Table 5 1,2-Dioxetanes prepared by [2+2]-cycloaddition with singlet oxygen.

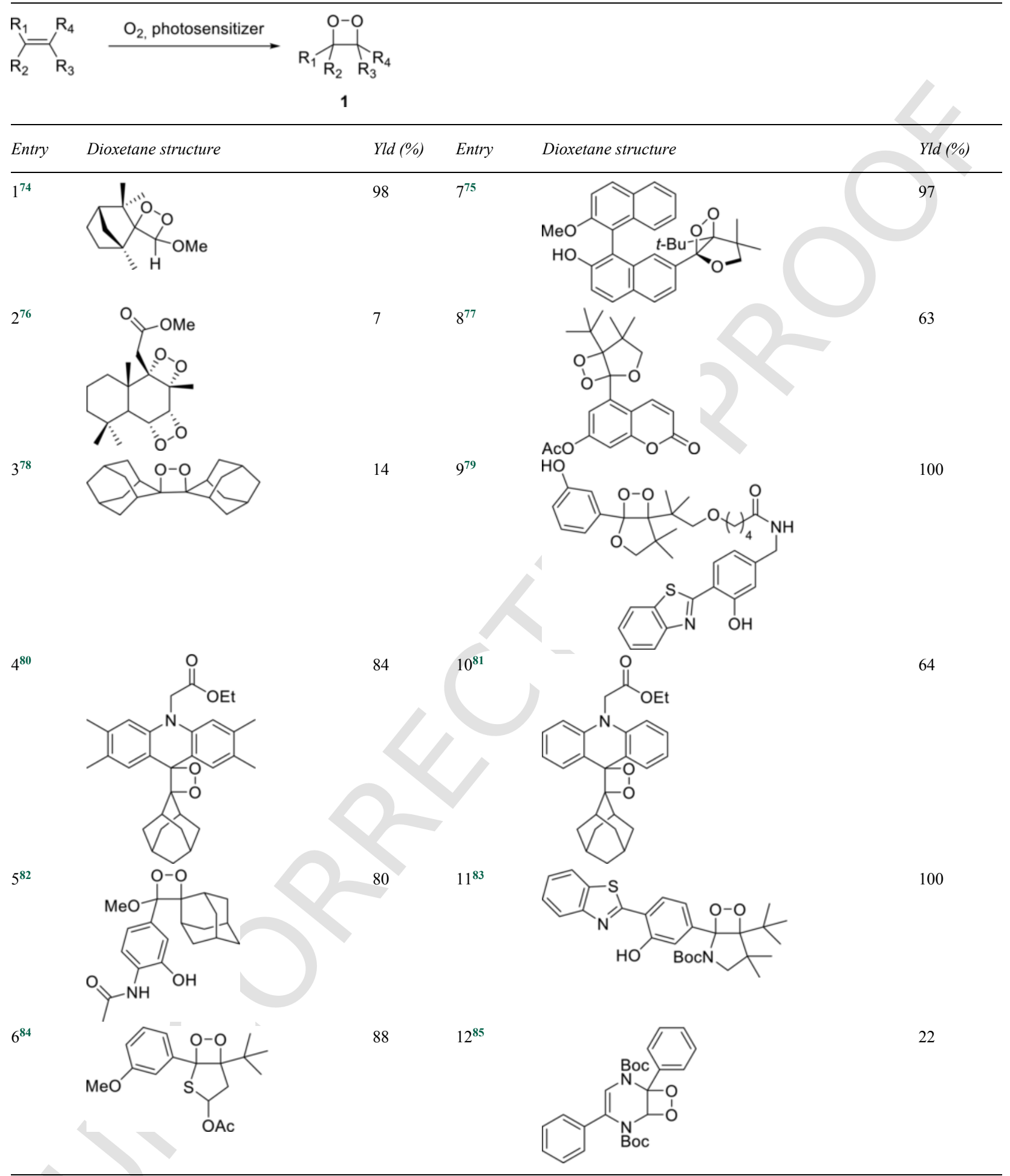

Data from (a) Ciscato, L. F. M. L.; Weiss, D.; Beckert, R.; Baader, W. J. J. Photochem. Photobiol. A Chem. 2011, 218, 41-47. (b) Kawashima, H.; Watanabe, N.; Ijuin, H. K.; Matsumoto, M. Luminescence 2013, 28, 696-704. (c) Ciocarlan, A.; Aricu, A.; Lungu, L.; Edu, C.; Barba, A.; Shova, S.; Mangalagiu, I. I.; D’Ambrosio, M.; Nicolescu, A.; Deleanu, C.; Vornicu, N. Synlett 2017, 28, 565-571. (d) Koči, J.; Grandclaude, V.; Massonneau, M.; Richard, J.-A.; Romieu, A.; Renard, P.-Y. Chem. Commun. 2011, 47, 6713-6715. (e) Clennan, E. L.; Liao, C. Phytochem. Phytobiol. 2014, 90, 344-357. (f) Watanabe, N.; 
Kino, H.; Watanabe, S.; Ijuin, H. K.; Yamada, M.; Matsumoto, M. Tetrahedron 2012, 68, 6079-6087. (g) Di Fusco, M.; Quintavalla, A.; Trombini, C.; Lombardo, M.; Roda, A.; Guardigli, M.; Mirasoli, M. J. Org. Chem. 2013, 78, 11238-11246. (h) Roda, A.; Di Fusco, M.; Quintavalla, A.; Guardigli, M.; Mirasoli, M.; Lombardo, M.; Trombini, C. Anal. Chem. 2012, 84, 9913-9919. (i) Hisamatsu, Y.; Fukiage, T.; Honma, K.; Balia, A. G.; Umezawa, N.; Kato, N.; Higuchi, T. Org. Lett. 2019, 21, 1258-1262. (j) Watanabe, N.; Sano, Y.; Suzuki, H.; Tanimura, M.; Ijuin, H. K.; Matsumoto, M. J. Org. Chem. 2010, 75 , 5920-5926. (k) Watanabe, N.; Kikuchi, M.; Maniwa, Y.; Ijuin, H. K.; Matsumoto, M. J. Org. Chem. 2010, 75, 879-884. (1) Tan, H.-B.; Song, X.-Q.; Yan, H. Heterocycl. Chem. 2015, 21, 83-88.<smiles>OC1(c2ccsc2)c2ccccc2-c2ccccc2C1(O)c1cccs1</smiles><smiles></smiles><smiles>c1ccc2c(c1)-c1ccccc1C13OC2(O1)c1ccsc13</smiles>

\section{Mechanism proposal}<smiles>OC1(c2ccsc2)c2ccccc2-c2ccccc2C1(O)c1cccs1</smiles><smiles>[O-]Nc1ccccc1C1(O)c2ccccc2-c2ccccc2C1(O)c1ccsc1</smiles>

\section{$(3,3)$}<smiles>O=C(O)C(O)=C1SC=CC1C1C=CSC1c1ccccc1-c1ccccc1</smiles>

1retro<smiles>O=C1C(=O)c2ccccc2-c2ccccc21</smiles>

46<smiles>COC12c3ccccc3-c3ccccc3C1(O)C13CC24CC=CC4=C1C=CS3</smiles>

49

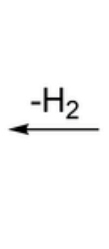<smiles>CO[C@]12c3ccccc3-c3ccccc3[C@@]1(O)[C@@]13SC=C[C@H]1[C@H]2C=CS3</smiles>

48
[O]<smiles>O=C1C(=O)c2ccccc2-c2ccccc21</smiles>

[2+2]<smiles>OC(=C1SC=CC1c1ccccc1-c1ccccc1C(O)C(O)C1C=CSC1)c1ccccc1</smiles>

47<smiles>OC12c3ccccc3-c3ccccc3C1(O)c1sccc12</smiles>

radical recombination<smiles>c1ccc2c(c1)-c1ccccc1C13OOC1(c1ccsc1O3)c1sccc1-2</smiles>

50

Scheme 23 Preparation and mechanistic proposal for 1,2-dioxetane 45 from a diol and sodium hydride. Based on Huq, C. A. M. A.; Sivakumar, S. Ind. J. Chem. 2014, 53B, 723-727. 


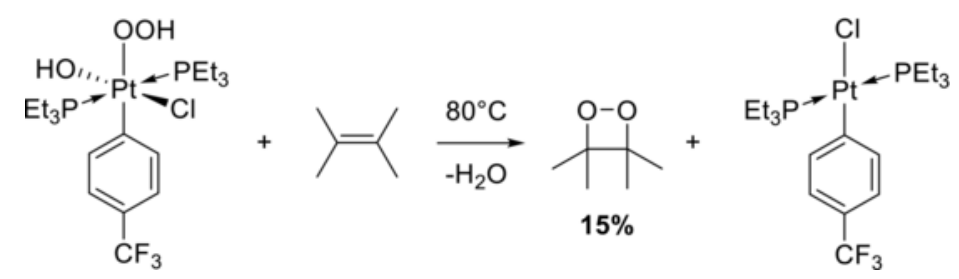

Scheme 24 Action of an hydroperoxo-hydroxo platinum(IV) complex on tetramethylethylene. Based on Wickramasinghe, L. A.; Sharp, P. R. J. Am. Chem. Soc. 2014, 136, 13979.

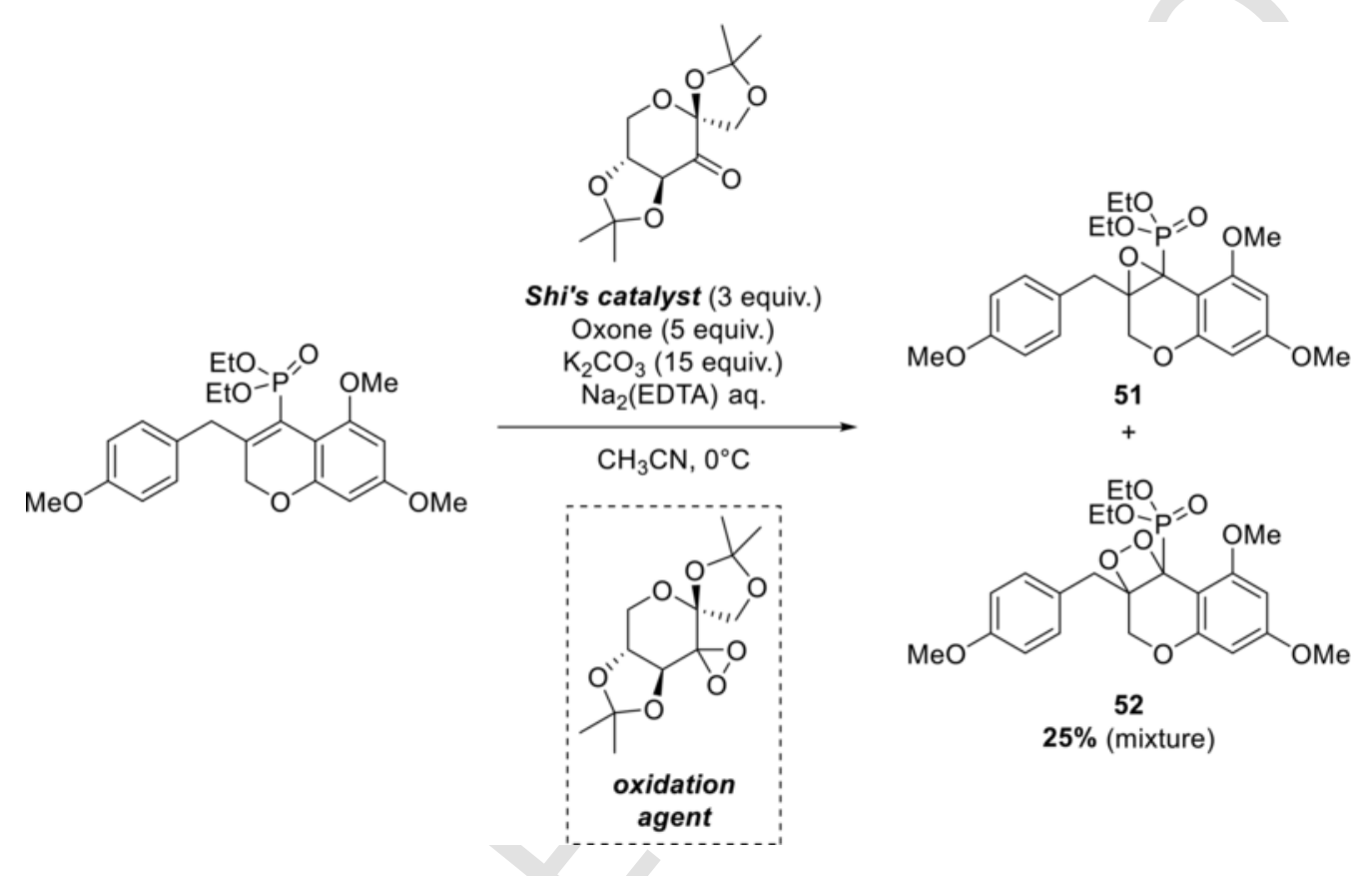

Scheme 25 Formation of dioxetane 52 as a byproduct in an epoxidation reaction with Shi's catalyst. Based on Krawczyk, E.; Koprowski, M.; Mielniczak, G.; Owsianik, K. Tetrahedron Asymmetry 2015, 26, 876-883.
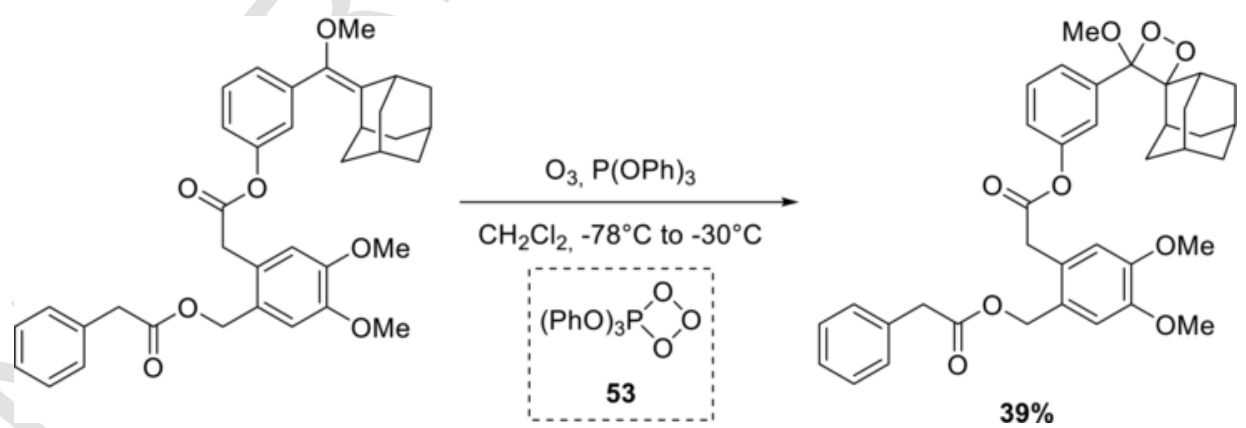

Scheme 26 Preparation of a 1,2-dioxetanone in the presence of ozone and triphenylphosphite. Based on Richard, J.-A.; Jean, L.; Schenkels, C.; Massonneau, M.; Romieu, A.; Renard, P.-Y. Org. Biomol. Chem. 2009, 7, 2941-2957. 


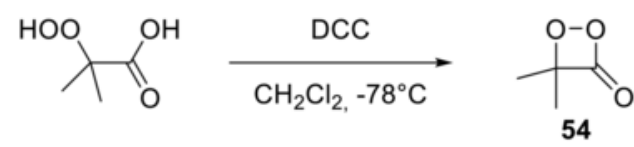

$(5 \%)$

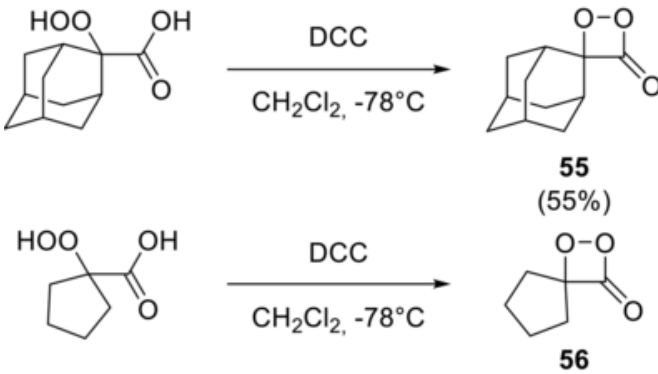

$(1 \%)$

Scheme 27 Preparation of 1,2-dioxetanone derivatives by lactonization of $\alpha$-peroxyacids with DCC. Based on Bartoloni, F.; de Oliveira, M. A.; Augusto, F. A.; Ciscato, L. F. M. L.; Bastos, E. L.; Baader, W. J. J. Braz. Chem. Soc. 2012, 23, 2093-2103.

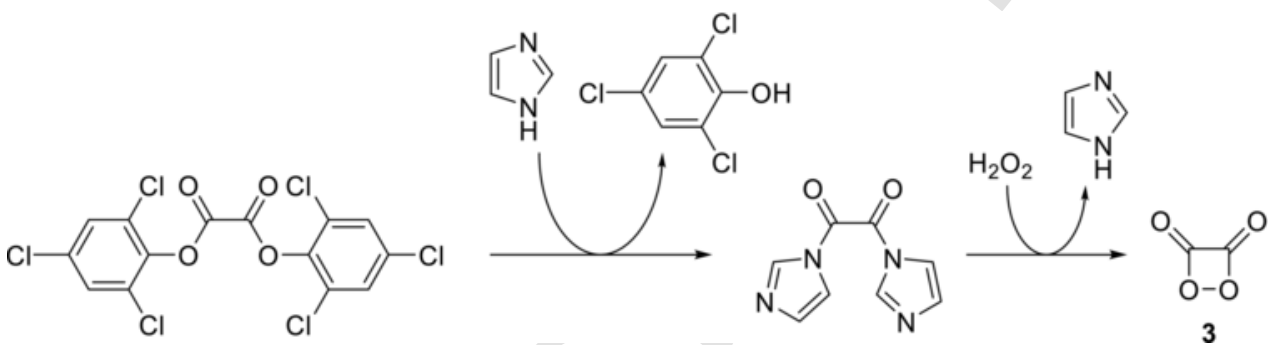

Scheme 28 In situ formation of 1,2-dioxetanedione 3 from 2,4,6-trichlorophenyloxalate. Based on Kazemi, S. Y.; Abedirad, S. M.; Zali, S. H.; Amiri, M. J. Lumin. 2012, 132, 1226-1231.

Table 6 Antiplasmodial and hemolytic data for artemisin $\mathbf{5 7}$ (taken as reference) and for 1,2-dioxetane derivatives 58-62.

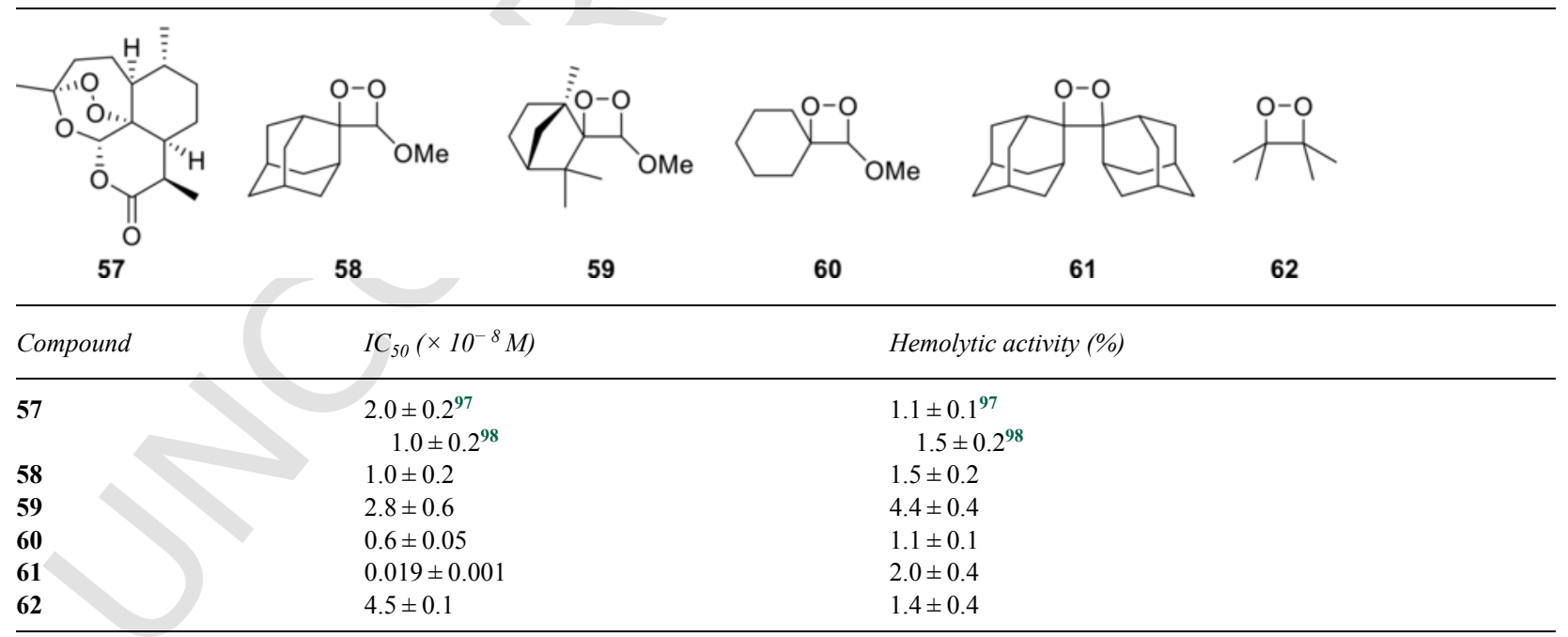

Data from (a) Lopes, N. S.; Yoshitake, A. M.; Silva, A. F.; Oliveira Jr., V. X.; Silva, L. S.; Pinheiro, A. A. S.; Ciscato, L. F. M. L. Chem. Biol. Drug Des. 2015, 86, 1373-1377. (b) Silva, A. F.; Oliveira Jr., V. X.; Silva, L. S.; Pinheiro, A. A. S.; Ciscato, L. F. M. L. Bioorg. Med. Chem. Lett. 2016, 26, $5007-5008$ 


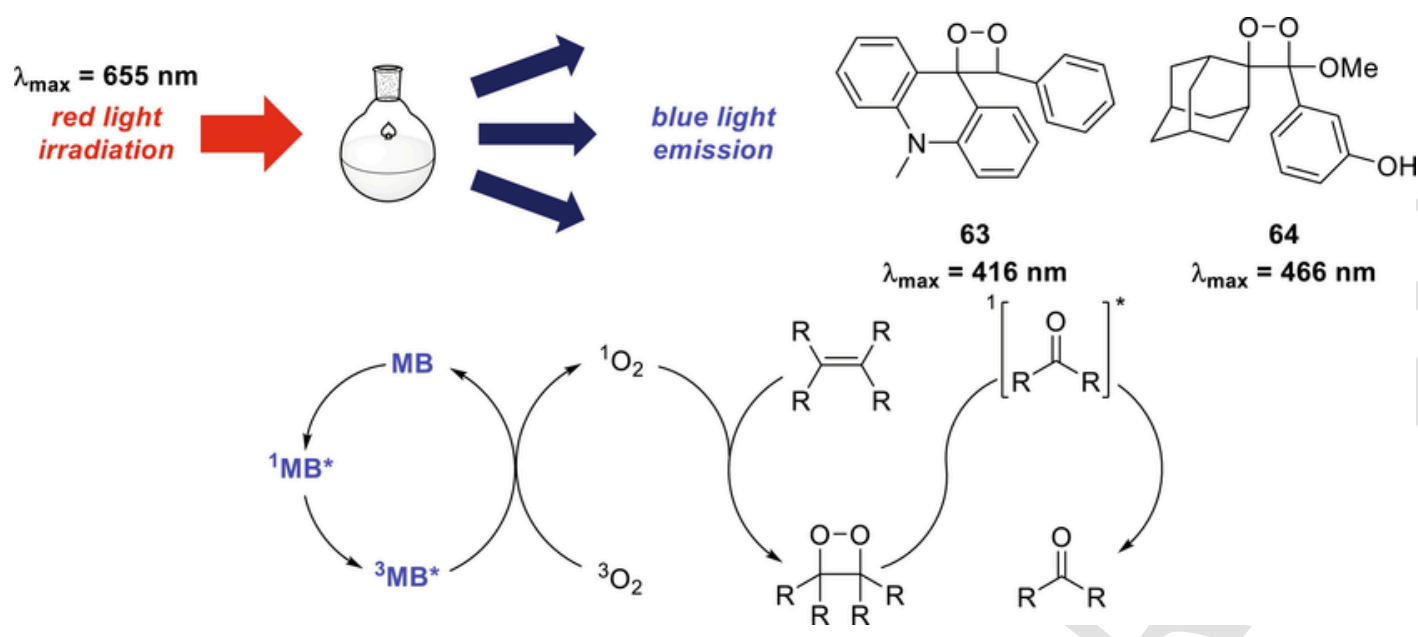

Scheme 29 Uphill energy conversion from red light to blue light. Based on Ciscato, L. F. M. L.; Weiss, D.; Beckert, R.; Bastos, E. L.; Bartoloni, F. H.; Baader, W. J. New J. Chem. 2011, 35, 773-775.

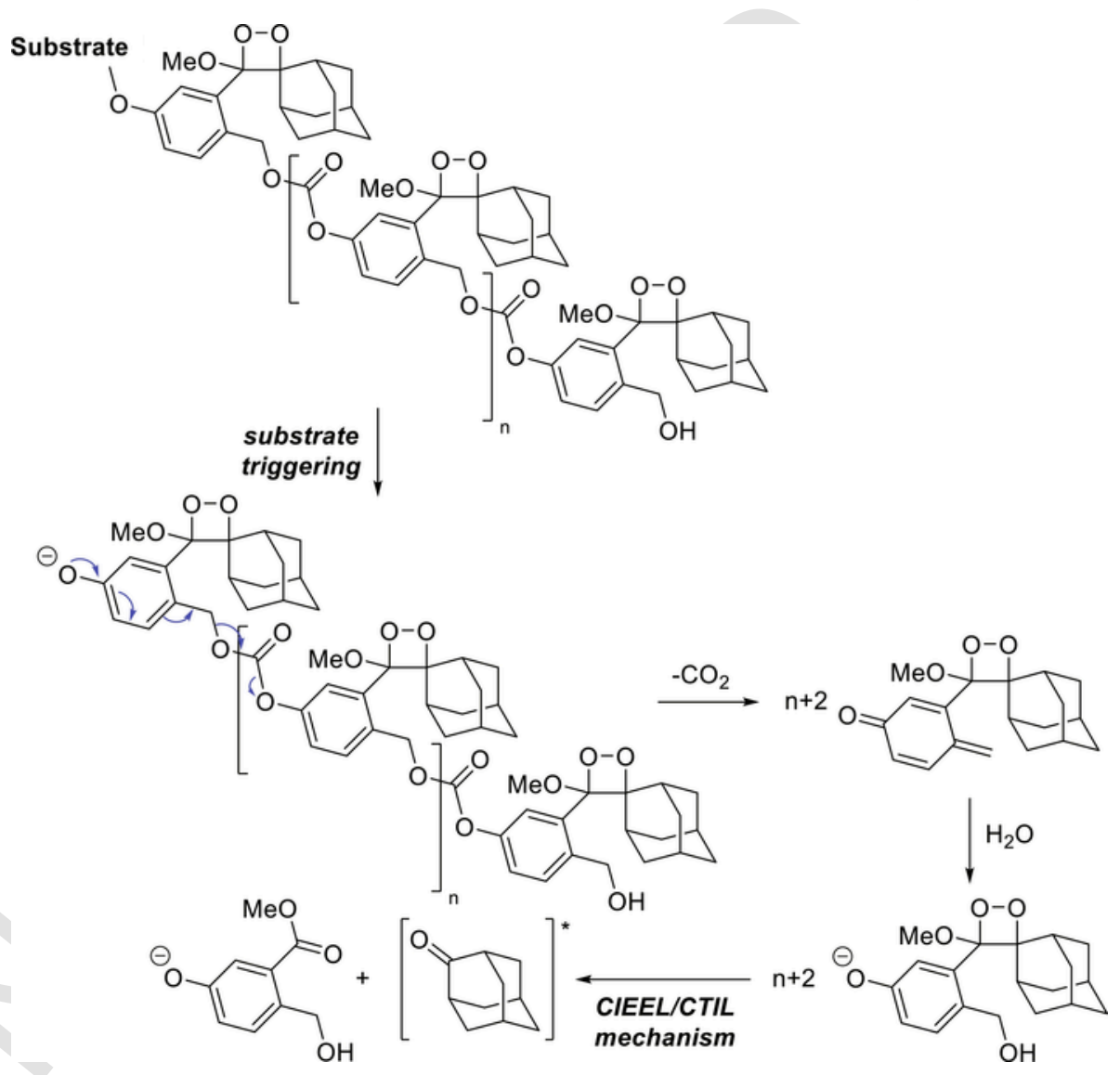

Scheme 30 Self-immolative chemiluminescent polymer. Based on Gnaim, S.; Shabat, D. J. Am. Chem. Soc. 2017, 139, $10002-10008$. 


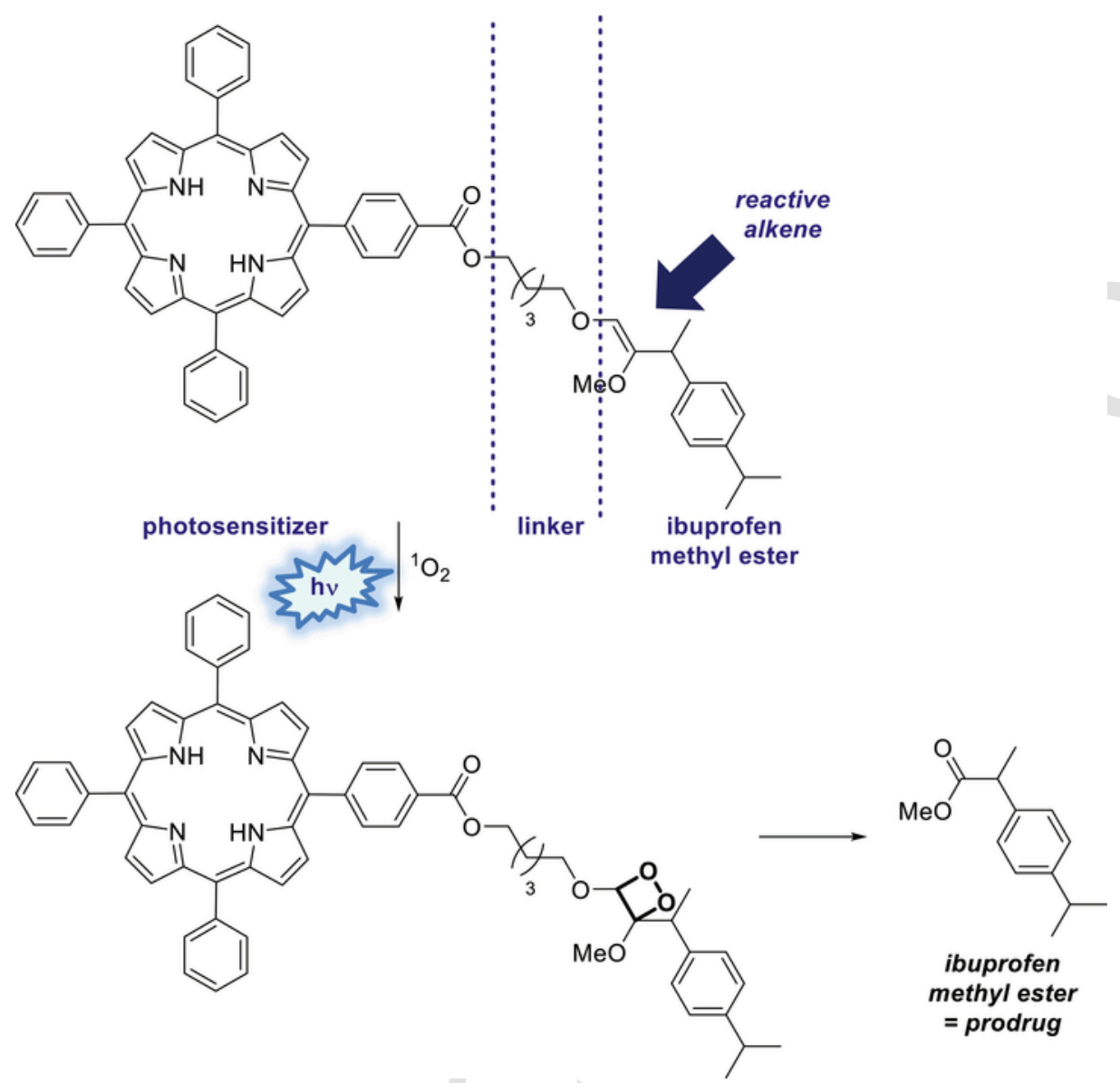

Scheme 31 Prodrug release via irradiation of light via in vivo formation of a 1,2-dioxetane scaffold. Based on Jiang, M. Y.; Dolphin, D. J. Am. Chem. Soc. 2008, 130, 4236-4237.

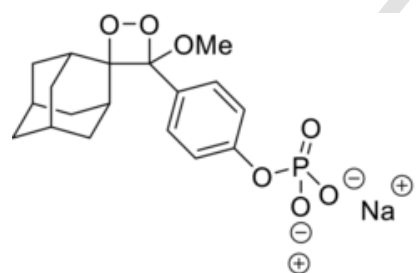

$\mathrm{Na}$

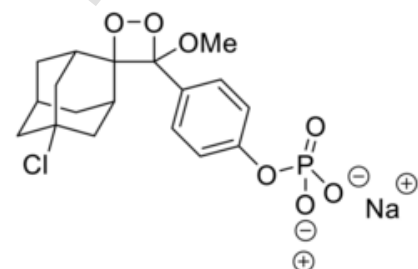

$\mathrm{Na}$

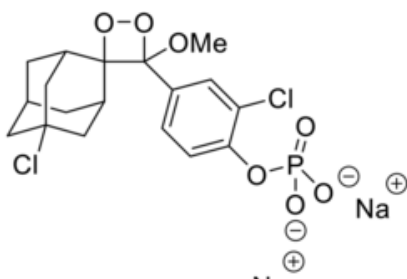

$\mathrm{Na}$

AMPPD $^{\circledR}$

CSPD $^{\circledR}$

CDP-Star ${ }^{\circledR}$

Scheme 32 Commercially available 1,2-dioxetane for bioassays.

\subsection{Energy conversion}

Unstable 1,2-dioxetanes 63 and $\mathbf{6 4}$ have been used in uphill energy conversion. ${ }^{99}$ With the help of methylene blue (MB), oxygen and red light irradiation $\left(\lambda_{\max }=655 \mathrm{~nm}\right)$, alkenes have been transformed in situ into unstable dioxetanes 63 and 64, which underwent decomposition with concomitant emission of blue light $\left(\lambda_{\max }=416 \mathrm{~nm}\right.$ for dioxetane 63 and $\lambda_{\max }=466 \mathrm{~nm}$ for dioxetane 64). Red light has therefore been converted into blue light (Scheme 29). 
Table 7 Detected biomolecules with the chemiluminescence phenomenon of 1,2-dioxetanes.

\begin{tabular}{|c|c|c|}
\hline Biomolecule detected & $\begin{array}{l}\text { Literature } \\
\text { reference }\end{array}$ & Specific application \\
\hline $\begin{array}{l}\text { IgA, IgG, IgM immunoglobulins and PEGylated } \\
\text { recombinant growth hormone }\end{array}$ & 106 & - \\
\hline HBsAg-specific DNA aptamers & 107 & Diagnosis for hepatitis B virus \\
\hline Leukocyte alkaline phosphatase & 108 & $\begin{array}{l}\text { Diagnosis of chronic myeloid leukemia and leukemoid } \\
\text { reactions }\end{array}$ \\
\hline Streptavidin alkaline phosphatase & 109 & $\begin{array}{l}\text { Diagnosis for hepatitis B virus (proof of } \\
\text { concept) - applicable to other pathogens }\end{array}$ \\
\hline Free prostate-specific antigen (f-PSA) in human serum & 110 & - \\
\hline Alkaline phosphatase and lactase & 111 & Early diagnosis of esophagus and stomach cancer \\
\hline$\alpha$-Fetoprotein (AFP) in human serum & 112 & Diagnosis of hepatocellular carcinoma \\
\hline Carbohydrate antigen 50 in human serum & 113 & - \\
\hline Tissue-nonspecific alkaline phosphatase & 114 & - \\
\hline$\beta$-Galactosidase & 115 & - \\
\hline Glutathione transferase & 116 & - \\
\hline Parovirus B19 nucleic acids & 117 & Diagnosis of parovirus B19 infection \\
\hline DNA sequences & 118 & - \\
\hline $\mathrm{P} 16^{\mathrm{INK} 4 \mathrm{~A}}$ marker and human papillomavirus (HPV) DNA & 119 & Diagnosis for cervical intra-epithelial neoplasia \\
\hline Cathepsin B & 120 & - \\
\hline $\mathrm{H}_{2} \mathrm{~S}$ in living animals & 121 & - \\
\hline Formaldehyde in living mice & 122 & - \\
\hline Protease enzymes & 123 & - \\
\hline Prokaryotic $\beta$-galactosidase reporter enzyme & 124 & Detects senescence in cells \\
\hline Nitroreductase & 125 & Diagnosis of tissue oxygenation (hypoxia) \\
\hline Vitamin $B_{12}$ in energy drinks & 126 & - \\
\hline Endogenous hydrogen polysulfide in living cells & 127 & \\
\hline
\end{tabular}

Data from (a) Kang, K.; Miao, J.; Cao, Z.; Lu, J. Analyst 2009, 134, 2246-2252. (b) Xi, Z.; Huang, R.; Li, Z.; He, N.; Wang, T.; Su, E.; Deng, Y. ACS Appl. Mater. Interfaces 2015, 7, 11215-11223. (c) Kanegae, M. P. P.; Ximenes, V. F.; Falcão, R. P.; Colturato, V. A. R.; de Mattos, E. R.; Brunetti, I. L.; de Fonseca, L. M. J. Clin. Lab. Anal. 2007, 21, 91-96. (d) Yang, H.; Liang, W.; He, N.; Deng, Y.; Li, Z. ACS Appl. Mater. Interfaces 2015, 7, 774-781. (e) Liu, R.; Wang, C.; Jiang, Q.; Zhang, W.; Yue, Z.; Liu, G. Anal. Chim. Acta 2013, 801, 91-96. (f) Park, J. Y.; Kirn, T. J.; Artis, D.; Waldmann, S. A.; Kricka, L. J. Luminescence 2010, 25, 463-465. (g) Wang, X.; Zhang, Q.-Y.; Li, Z.-J.; Ying, X.-T.; Lin, J.-M. Clin. Chim. Acta 2008, 393, 90-94. (h) Wang, X.; Lin, J.-M.; Ying, X. Anal. Chim. Acta 2007, 598, 261-267. (i) Sergienko, E. A.; Millán, J. L. Nat. Protoc. 2010, 5, 1431-1439. (j) Liu, L.; Mason, R. P. PLoS One 2010, 5, e12024. (k) Ito, M.; Shibata, A.; Zhang, J.; Hiroshima, M.; Sako, Y.; Nakano, Y.; Kojima-Aikawa, K.; Mannervik, B.; Shuto, S.; Ito, Y.; Morgensten, R.; Abe, H. ChemBioChem 2012, 13, 1428-1432. (1) Bonvicini, F.; Mirasoli, M.; Gallinella, G.; Zerbini, M.; Musiani, M.; Roda, A. Analyst 2007, 132, 519-523. (m) (i) Li, Z.; Li, W.; Cheng, Y.; Hao, L. Analyst 2008, 133, 1164-1168. (ii) Xin, L.; Cao, Z.; Lau, C.; Kai, M.; Lu, J. Luminescence 2010, 25, 336-342. (n) Mirasoli, M.; Guardigli, M.; Simoni, P.; Venturoli, S.; Ambretti, S.; Musiani, M.; Roda, A. Anal. Bioanal. Chem. 2009, 394, 981-987. (o) (i) Roth-Konforti, M. E.; Bauer, C. R.; Shabat, D. Angew. Chem. Int. Ed. 2017, 56, 15633-15638. (ii) Ryan, L. S.; Lippert, A. R. Angew. Chem. Int. Ed. 2018, 57, 622-624. (p) Cao, J.; Lopez, R.; Thacker, J. M.; Moon, J. Y.; Jiang, C.; Morris, S. N. S.; Bauer, J. H.; Tao, P.; Masonc, R. P.; Lippert, A. R. Chem. Sci. 2015, 6, 1979-1985. (q) Bruemmer, K. J.; Green, O.; Su, T. A.; Shabat, D.; Chang, C. J. Angew. Chem. Int. Ed. 2018, 57, 7508-7512. (r) Richard, J.-A.; Jean, L.; Romieu, A.; Massonneau, M.; Noack-Fraissignes, P.; Reanrd, P.-Y. Org. Lett. 2007, 9, 4853-4855. (s) Bassaneze, V.; Miyakawa, A. A.; Krieger, J. E. Anal. Biochem. 2008, 372, 198-203. (t) Cao, J.; Campbell, J.; Liu, L.; Mason, R. P.; Lippert, A. R. Anal. Chem. 2016, 88, 4995-5002. (u) Selvakumar, L. S.; Thakur, M. S. Anal. Chim. Acta 2012, 722, 107-113. (v) Li, J.-B.; Wang, Q.; Liu, H.-W.; Yuan, L.; Zhang, X.-B. Chem. Commun. 2019, 55, 4487-4490.

\subsection{Polymer science}

The group of Shabat recently developed self-immolative chemiluminescent polymers, ${ }^{100}$ functional macromolecules that undergo a domino-like disassembly from head to tail upon activation. These new types of polymers have been discovered by the same group in the late 2000s. ${ }^{101}$ By combining Schaap's adamantylidene-dioxetane and a $p$-hydroxybenzyl alcohol unit, they were able to polymerize and disassemble the formed polymer, generating blue light through a quinone-methide elimination followed by a dioxetanone decomposition via a CIEEL/CTIL mechanism (Scheme 30). The advantage of this material is that the light emitted is more intense and lasts longer because of the numerous dioxetane motifs included in the chain. 


\subsection{Drug release}

The formation and decomposition of 1,2-dioxetane scaffolds has been used for the site-specific prodrug release in diseased cells. Usually, prodrug release is made by enzymatic activation and can be site-selective when specific enzymes, as well as appropriate chemical environment, are close to the drug target. As activation can sometimes be difficult, some groups tried to develop new systems where visible light is used to trigger the release of the drug. Besides, the photodynamic therapy uses biocompatible photosensitizers to transform triplet oxygen into singlet oxygen inside the organism.

In 2008, the group of Dolphin set up a system consisting in a photosensitizer, a biocompatible linker and a prodrug possessing a carbonyl function (ketone, ester or lactone). ${ }^{102}$ They showed, based on GC and NMR experiments, that efficient prodrug release yields could be obtained in organic solvents while using a biocompatible porphyrin-based sensitizer with a pentanediol linker (Scheme 31). The same kind of system triggered by light has been studied for the release of a sensitizer drug bound to a silica support. ${ }^{103}$

The group of Shabat also tested the same kind of trigger-spacer-prodrug system in vivo by releasing the cytotoxic peptide prodrug monomethyl auristatin E, but this time activated by a $\beta$-galactosidase enzyme. ${ }^{104}$ They could monitor the prodrug activation in real-time using the chemiluminescence of the dioxetanes moiety present in the spacer.

\subsection{Bioassays and medical diagnosis}

The chemiluminescence phenomenon of 1,2-dioxetanes has been used for a long time to evaluate the presence of several biological molecules within a sample to analyze. These tests are called CLEIA for ChemiLuminescence Enzyme ImmunoAssay. In particular, the 1,2-dioxetanes undergoing a CIEEL/CTIL/GRCTIL mechanism when they degrade are of great interest because of their chemiluminescence efficiency. Moreover, some of these 1,2-dioxetanes are commercially available, though relatively expensive, under the names AMPPD ${ }^{\circledR}, \mathrm{CSPD}{ }^{\circledR}$, and CDP-Star ${ }^{\circledR}$ for example (Scheme 32). If not commercially available, new dioxetanes used for bioassays have been designed for specific purposes. ${ }^{105}$ The light emitted after 1,2-dioxetane degradation can be recorded via chemiluminescent imaging of culture cell plates or via other in vivo imaging techniques.

These last years, there have been a huge number of publications describing the use of different 1,2-dioxetanes in the field of the detection of specific biomolecules. Table 7 reports the major molecules that can be detected in living organisms by chemiluminescence. If interested, the reader is strongly advised to look at the respective references.

\section{References}

1. J.W. Timberlake, E.S. Elder, Comprehensive Heterocyclic Chemistry, 1st ed.Pergamon, Oxford, 1984449-489.

2. C.R. Saha-Möller, W. Adam, Comprehensive Heterocyclic Chemistry, 2nd ed., Pergamon, Oxford, 19961041-1082.

3. D.K. Taylor, Comprehensive Heterocyclic Chemistry, 3rd ed., Pergamon, Oxford, 2008775-794.

4. For a recent review, see: Vacher, M.; Fdez. Galván, I.; Ding, B.-W.; Schramm, S.; Berraud-Pache, R.; Naumov, P.; Ferré, N.; Liu, Y.-J.; Navizet, I.; Roca-Sanjuán, D.; Baader, W. J.; Lindh, R. Chem. Rev. 2018, 118, 6927-6974.

5. For a review mentioning mechanistic studies on 1,2-dioxetane decomposition, see: Carpenter, B. K. Chem. Soc. Rev. 2006, 35, $736-747$.

6. W. Adam, W.J. Baader, J. Am. Chem. Soc. 107 (1985) 410-416.

7. E.L. Bastos, W.J. Baader, ARKIVOC viii (2007) 257-272.

8. S. Malpathak, X. Ma, W.L. Hase, J. Chem. Phys. 148 (2018), article 164309.

9. M. Vacher, A. Brakestad, H.O. Karlsson, I. Fdez. Galván, R. Lindh, J. Chem. Theory Comput. 13 (2017) $2448-2457$.

10. (a) M. Reguero, F. Bernardi, M. Olivucci, M.A. Robb, J. Am. Chem. Soc. 113 (1991) 1566-1572;(b) S. Wilsey, F. Bernardi, M. Olivucci, M.A. Robb, S. Murphy, W. Adam, J. Phys. Chem. A 103 (1999) 1669-1677;(c) C. Tanaka, J. Tanaka, J. Phys. Chem. A 104 (2000) 2078-2090;(d) R. Sun, K. Park, W.A. de Jong, H. Lischka, T.L. Windus, W.L. Hase, J. Chem. Phys. 137 (2012), article 044305.

11. L. De Vico, Y.-J. Liu, J.W. Krogh, R. Lindh, J. Chem. Phys. A 111 (2007) 8013-8019.

12. P. Farahani, D. Roca-Sanjuán, F. Zapata, R. Lindh, J. Chem. Theory Comput. 9 (2013) 5404-5411.

13. A.C. West, M.W. Schmidt, M.S. Gordon, K. Ruedenberg, J. Chem. Phys. 139 (2013), article 234107.

14. A.C. West, M.W. Schmidt, M.S. Gordon, K. Ruedenberg, J. Phys. Chem. A 119 (2015) 10360-10367.

15. A.C. West, M.W. Schmidt, M.S. Gordon, K. Ruedenberg, J. Phys. Chem. A 119 (2015) 10368-10375.

16. A.C. West, M.W. Schmidt, M.S. Gordon, K. Ruedenberg, J. Phys. Chem. A 119 (2015) 10376-10389.

17. (a) W. Adam, Adv. Heterocycl. Chem. 21 (1977) 437;(b) W. Adam, W.J. Baader, Angew. Chem. Int. Ed. 23 (1984) 166-167;(c) W. Adam, W.J. Baader, J. Am. Chem. Soc. 107 (1985) 410-416.

18. M. Vacher, P. Farahani, A. Valentini, L.M. Frutos, H.O. Karlsson, I. Fdez. Galán, R. Lindh, J. Phys. Chem. Lett. 8 (2017) $3790-3794$.

19. (a) W. Adam, J.C. Liu, J. Am. Chem. Soc. 94 (1972) 2894-2895;(b) G.B. Schuster, S.P. Schmidt, J. Am. Chem. Soc. 102 (1980) 306-314;(c) N.J. Turro, M.F. Chow, J. Am. Chem. Soc. 102 (1980) 5058-5064.

20. (a) S.P. Schmidt, G.B. Schuster, J. Am. Chem. Soc. 100 (1978) 5559-5561;(b) W. Adam, G.A. Simpson, F. Yany, J. Phys. Chem. 78 (1974) 2559-2569.

21. F. Liu, Y. Liu, L. De Vico, R. Lindh, J. Am. Chem. Soc. 131 (2009) 6181.

22. L. Pinto da Silva, J.C.G. Esteves da Silva, J. Comput. Chem. 33 (2012) 2118-2123.

23. See a footnote and references cited in: Roca-Sanjuán, D.; Lundberg, M.; Mazzioti, D. A.; Lindh, R. J. Comput. Chem. 2012, 33, $2124-2126$.

24. L. Pinto da Silva, J.C.G. Esteves da Silva, ScienceJet 1 (2012), article 29.

25. L. Pinto da Silva, J.C.G. Esteves da Silva, J. Comput. Chem. 33 (2012) 2127-2130.

26. L. Yue, D. Roca-Sanjuán, R. Lindh, N. Ferré, Y.-J. Liu, J. Chem. Theory Comput. 8 (2012) 4359-4363.

27. L. Pinto da Silva, J.C.G. Esteves da Silva, Int. J. Quantum Chem. 113 (2013) 1709-1716. 
28. A. Francés-Monerris, I. Fernández-Galván, R. Lindh, D. Roca-Sanjuán, Theor. Chem. Acc. 136 (2017), article 70.

29. L. Pinto da Silva, J.C.G. Esteves da Silva, ChemPhysChem 14 (2013) 1071-1079.

30. W. Adam, O. Cueto, J. Am. Chem. Soc. 101 (1979) 6511-6515.

31. P. Farahani, M.A. Oliveira, I. Fernández Galván, W.J. Baader, RSC Adv. 7 (2017) 17462-17472.

32. F.H. Bartoloni, M.A. Oliveira, F.A. Augusto, L.F.M.L. Ciscato, E.L. Bastos, W.J. Baader, J. Braz. Chem. Soc. 23 (2012) $2093-2103$.

33. F. Liu, Y. Liu, L. De Vico, R. Lindh, Chem. Phys. Lett. 484 (2009) 69-75.

34. L. Pinto da Silva, J.C.G. Esteves da Silva, Struct. Chem. 25 (2014) 1075-1081.

35. For more examples, see: (a) McCapra, F. Pure Appl. Chem. 1970, 24, 611-629. (b) Kearns, D. R. Chem. Rev. 1971, 71, 395-427. (c) Richardson, W. H.; O’Neil, H. E. J. Am. Chem. Soc. 1972, 94, 8665-8668. (d) Yue, L.; Liu, Y. J.; Fang, W. H. J. Am. Chem. Soc. 2012, 134, 11632-11639.

36. Y. Ando, K. Niwa, N. Yamada, T. Enomoto, T. Irie, H. Kubota, Y. Ohmiya, H. Akiyama, Nat. Photonics 2 (2008) 44-47.

37. L. Greenman, D.A. Mazziotti, J. Chem. Phys. 133 (2010), article 164110.

38. C.-G. Min, A.-M. Ren, X.-N. Li, J.-F. Guo, L.-Y. Zou, Y. Sun, J.D. Goddard, C.-C. Sun, Chem. Phys. Lett. 506 (2011) $262-275$.

39. For a review, see: McCapra, F. Methods Enzymol. 2000, 305, 3-47.

40. L. Yue, Y.-J. Liu, W.-H. Fang, J. Am. Chem. Soc. 134 (2012) 11632-11639.

41. L. Pinto da Silva, A.J.M. Santos, J.C.G. Esteves da Silva, J. Phys. Chem. A 117 (2013) 94-100

42. L. Pinto da Silva, J. Vieira, J.C.G. Esteves da Silva, Chem. Phys. Lett. 543 (2012) 137-141.

43. R. Berraud-Pache, R. Lindh, I. Navizet, J. Phys. Chem. B 122 (2018) 5173-5182.

44. (a) F.H. Johnson, O. Shimomura, Y. Saiga, L.C. Gershman, G.T. Reynolds, J.R. Waters, J. Cell. Comp. Physiol. 60 (1962) 85-103;(b) O. Shimomura, F.H. Johnson, Photochem. Photobiol. 12 (1970) 291-295.

45. O. Shimomura, F.H. Johnson, Nature 227 (1970) 1356-1357.

46. H. Isobe, S. Yamanaka, S. Kuramitsu, K. Yamaguchi, J. Am. Chem. Soc. 130 (2008) 132-139.

47. D. Roca-Sanjuán, M.G. Delcey, I. Navizet, N. Ferré, Y.-J. Liu, R. Lindh, J. Chem. Theory Comput. 7 (2011) 4060-4069.

48. Z.J. Liu, G.A. Stepanyuk, E.S. Vysotski, J. Lee, S.V. Markova, N.P. Malikova, B.C. Wang, Proc. Natl. Acad. Sci. U. S. A. 103 (2006) $2570-2575$

49. (a) H. Isobe, Y. Takano, M. Okumura, S. Kuramitsu, K. Yamaguchi, J. Am. Chem. Soc. 127 (2005) 8667-8679;(b) T. Hirano, Y. Takahashi, H. Kondo, S. Maki, S. Kojima, H. Ikeda, H. Niwa, Photochem. Photobiol. Sci. 7 (2008) 197.

50. B.-W. Ding, P. Naumov, Y.-J. Liu, J. Chem. Theory Comput. 11 (2015) 591-599.

51. L. Pinto da Silva, C.M. Magalhães, J.C.G. Esteves da Silva, ChemistrySelect 1 (2016) 3343.

52. See also: Naumov, P.; Wu, C.; Liu, Y.-J.; Ohmiya, Y. PhotoChem. Photobiol. Sci. 2012, 11, 1151.

53. R. Bos, N.W. Barnett, G.A. Dyson, K.F. Lim, R.A. Russel, S.P. Watson, Anal. Chim. Acta 502 (2004) 141-147.

54. B.I. Dunlap, I.V. Schweigert, A.P. Purdy, A.W. Snow, A. Hu, J. Chem. Phys. 138 (2013), article 134304.

55. R. Bos, S.A. Tonkin, G.R. Hanson, C.M. Hindson, K.F. Lim, N.W. Barnett, J. Am. Chem. Soc. 131 (2009) 2770-2771

56. L. Pinto da Silva, J.C.G. Esteves da Silva, J. Phys. Org. Chem. 26 (2013) 659-663.

57. D.J. Beard, S.A. Barakat, N.B. Lockhart, C.R. Pace, C.U. Pittman Jr., B.W. Hamil, S. Saebo, Struct. Chem. 23 (2012) 351-357.

58. S.-G. Chen, J.-J. Chen, K. Gao, Chem. Pharm. Bull. 55 (2007) 1181-1184.

59. D. Yang, Z.-Q. Cheng, L. Yang, B. Hou, J. Yang, X.-N. Li, C.-T. Zi, F.-W. Dong, Z.-H. Liu, J. Zhou, Z.-T. Ding, J.-M. Hu, J. Nat. Prod. 81 (2018) 227.

60. Q.-F. Liu, W.-L. Chen, J. Tang, W.-M. Zhao, Helv. Chim. Acta 90 (2007) 1745-1750.

61. H. Li, L. Li, Q. Zheng, C. Kuroda, Q. Wang, Molecules 17 (2012) 5219-5224.

62. T.-H. Lee, C.-K. Lu, Y.-H. Kuo, J.-M. Lo, C.-K. Lee, Helv. Chim. Acta 91 (2008) 79-84.

63. J. Ren, J.J. Qin, X.R. Cheng, S.K. Yan, H.Z. Jin, W.D. Zhang, Arch. Pharm. Res. 36 (2013) 1319-1325.

64. R. Wen, H. Lv, Y. Jiang, P. Tu, Bioorg. Med. Chem. Lett. 28 (2018) 1050-1055.

65. X. Liu, J. Fu, X.-J. Yao, J. Yang, L. Liu, T.-G. Xie, P.-C. Jiang, Z.-H. Jiang, G.-Y. Zhu, J. Nat. Prod. 81 (2018) 1333-1342.

66. Y. Chen, A.J.H. Spiering, S. Karthikeyan, G.W.M. Peters, E.W. Meijer, R.P. Sijbesma, Nat. Chem. 4 (2012) 559-562.

67. Y. Chen, R.P. Sijbesma, Macromolecules 47 (2014) 3797-3805.

68. (a) S.N. Zhurkov, Int. J. Fract. Mech. 1 (1965) 311-323;(b) K.L. DeVries, Rubber Chem. Technol. 48 (1975) 445-461

69. C.K. Lee, D.A. Davis, S.R. White, J.S. Moore, N.R. Sottos, P.V. Braun, J. Am. Chem. Soc. 132 (2010) 16107-16111.

70. (a) S.-J. Kim, D.H. Reneker, Polym. Bull. 31 (1993) 367-374;(b) B.R. Crenshaw, C. Weder, Macromolecules 39 (2006) 9581-9589;(c) R.A. Koevoets, S. Karthikeyan, P.C.M.M. Magusin, E.W. Meijer, R.P. Sijbesma, Macromolecules 42 (2009) 2609-2617.

71. J.M. Clough, C. Creton, S.L. Craig, R.P. Sijbesma, Adv. Funct. Mater. 26 (2016) 9063-9074.

72. W. Yuan, Y. Yuan, F. Yang, M. Wu, Y. Chen, Macromolecules 51 (2018) 9019-9025.

73. L. Yu, L. Ren, R. Yi, R. Guo, Synth. Commun. 41 (2011) 2530-2538.

74. L.F.M.L. Ciscato, D. Weiss, R. Beckert, W.J. Baader, J. Photochem. Photobiol. A Chem. 218 (2011) 41-47.

75. H. Kawashima, N. Watanabe, H.K. Ijuin, M. Matsumoto, Luminescence 28 (2013) 696-704.

76. A. Ciocarlan, A. Aricu, L. Lungu, C. Edu, A. Barba, S. Shova, I.I. Mangalagiu, M. D’Ambrosio, A. Nicolescu, C. Deleanu, N. Vornicu, Synlett 28 (2017) 565-571.

77. J. Koči, V. Grandclaude, M. Massonneau, J.-A. Richard, A. Romieu, P.-Y. Renard, Chem. Commun. 47 (2011) 6713-6715.

78. E.L. Clennan, C. Liao, Phytochem. Phytobiol. 90 (2014) 344-357.

79. N. Watanabe, H. Kino, S. Watanabe, H.K. Ijuin, M. Yamada, M. Matsumoto, Tetrahedron 68 (2012) 6079-6087.

80. M. Di Fusco, A. Quintavalla, C. Trombini, M. Lombardo, A. Roda, M. Guardigli, M. Mirasoli, J. Org. Chem. 78 (2013) 11238-11246.

81. A. Roda, M. Di Fusco, A. Quintavalla, M. Guardigli, M. Mirasoli, M. Lombardo, C. Trombini, Anal. Chem. 84 (2012) $9913-9919$.

82. Y. Hisamatsu, T. Fukiage, K. Honma, A.G. Balia, N. Umezawa, N. Kato, T. Higuchi, Org. Lett. 21 (2019) 1258-1262.

83. N. Watanabe, Y. Sano, H. Suzuki, M. Tanimura, H.K. Ijuin, M. Matsumoto, J. Org. Chem. 75 (2010) 5920-5926.

84. N. Watanabe, M. Kikuchi, Y. Maniwa, H.K. Ijuin, M. Matsumoto, J. Org. Chem. 75 (2010) 879-884.

85. H.-B. Tan, X.-Q. Song, H. Yan, Heterocycl. Chem. 21 (2015) 83-88.

86. C.A.M.A. Huq, S. Sivakumar, Indian J. Chem. 53B (2014) 723-727.

87. L.A. Wickramasinghe, P.R. Sharp, J. Am. Chem. Soc. 136 (2014) 13979.

88. E. Krawczyk, M. Koprowski, G. Mielniczak, K. Owsianik, Tetrahedron Asymmetry 26 (2015) 876-883.

89. Y. Tu, Z.-X. Wang, Y. Shi, J. Am. Chem. Soc. 118 (1996) 980-9807.

90. J.-A. Richard, L. Jean, C. Schenkels, M. Massonneau, A. Romieu, P.-Y. Renard, Org. Biomol. Chem. 7 (2009) 2941-2957. 
91. B. Neises, W. Steglich, Angew. Chem. Int. Ed. 17 (1978) 522-524.

92. R. Chong, J.-E.R. Rho, H.J. Yoon, T.-H.D. Rho, P.S. Park, Y.-H. Kim, J.H. Lee, Biosens. Biolectron. 32 (2012) 19-23.

93. K. Zargoosh, M. Shamsipur, M. Qandalee, M. Piltan, L. Moradi, Spectrochim. Acta A 81 (2011) 679-683.

94. L. Park, H. Bae, Y.-T. Kim, J.H. Lee, Anal. Methods 3 (2011) 156-160.

95. (a) M. Hosseini, S.D. Abkenar, M.J. Chaichi, M. Shamsipur, Acta Chim. Slov. 55 (2008) 562-569;(b) S.Y. Kazemi, S.M. Abedirad, S.H. Zali, M. Amiri, J. Lumin. 132 (2012) 1226-1231.

96. P. Salas, C. Herrmann, C. Orvig, Chem. Rev. 113 (2013) 3450-3492.

97. N.S. Lopes, A.M. Yoshitake, A.F. Silva, V.X. Oliveira Jr., L.S. Silva, A.A.S. Pinheiro, L.F.M.L. Ciscato, Chem. Biol. Drug Des. 86 (2015) $1373-1377$.

98. A.F. Silva, V.X. Oliveira Jr., L.S. Silva, A.A.S. Pinheiro, L.F.M.L. Ciscato, Bioorg. Med. Chem. Lett. 26 (2016) 5007-5008.

99. L.F.M.L. Ciscato, D. Weiss, R. Beckert, E.L. Bastos, F.H. Bartoloni, W.J. Baader, New J. Chem. 35 (2011) 773.

100.S. Gnaim, D. Shabat, J. Am. Chem. Soc. 139 (2017) 10002-10008.

101.(a) A. Sagi, R. Weinstain, N. Karton, D. Shabat, J. Am. Chem. Soc. 130 (2008) 5434;(b) R. Weinstain, A. Sagi, N. Karton, D. Shabat, Chem. Eur. J. 14 (2008) 6857;(c) R. Weinstain, P.S. Baran, D. Shabat, Bioconjug. Chem. 20 (2009) 1783.

102.M.Y. Jiang, D. Dolphin, J. Am. Chem. Soc. 130 (2008) 4236-4237.

103.D. Bartusik, M. Minnis, G. Ghosh, A. Greer, J. Org. Chem. 78 (2013) 8537-8544.

104.S. Gnaim, A. Scomparin, S. Das, R. Blau, R. Satchi-Fainaro, D. Shabat, Angew. Chem. Int. Ed. 57 (2018) 9033.

105.(a) N. Hananya, A. Eldar-Boock, C.R. Bauer, R. Satchi-Fainaro, D. Shabat, J. Am. Chem. Soc. 138 (2016) 13438-13446;(b) O. Green, T. Eilon, N. Hananya, S. Gutkin, C.R. Bauer, D. Shabat, ACS Cent. Sci. 3 (2017) 349-358;(c) T. Eilon-Schaffer, M. Roth-Konforti, A. Eldar-Boock, R. Satchi-Fainaro, D. Shabat, Org. Biomol. Chem. 16 (2018) 1708-1712;(d) S. Gnaim, A. Scomparin, A. Eldar-Boock, C.R. Bauer, R. Satchi-Fainaro, D. Shabat, Chem. Sci. 10 (2019) 2945-2955.

106.K. Kang, J. Miao, Z. Cao, J. Lu, Analyst 134 (2009) 2246-2252.

107.Z. Xi, R. Huang, Z. Li, N. He, T. Wang, E. Su, Y. Deng, ACS Appl. Mater. Interfaces 7 (2015) 11215-11223.

108.M.P.P. Kanegae, V.F. Ximenes, R.P. Falcão, V.A.R. Colturato, E.R. de Mattos, I.L. Brunetti, L.M. de Fonseca, J. Clin. Lab. Anal. 21 (2007) 91-96.

109.H. Yang, W. Liang, N. He, Y. Deng, Z. Li, ACS Appl. Mater. Interfaces 7 (2015) 774-781.

110.R. Liu, C. Wang, Q. Jiang, W. Zhang, Z. Yue, G. Liu, Anal. Chim. Acta 801 (2013) 91-96.

111.J.Y. Park, T.J. Kirn, D. Artis, S.A. Waldmann, L.J. Kricka, Luminescence 25 (2010) 463-465.

112.X. Wang, Q.-Y. Zhang, Z.-J. Li, X.-T. Ying, J.-M. Lin, Clin. Chim. Acta 393 (2008) 90-94.

113.X. Wang, J.-M. Lin, X. Ying, Anal. Chim. Acta 598 (2007) 261-267.

114.E.A. Sergienko, J.L. Millán, Nat. Protoc. 5 (2010) 1431-1439.

115.L. Liu, R.P. Mason, PLoS One 5 (2010), e12024.

116.M. Ito, A. Shibata, J. Zhang, M. Hiroshima, Y. Sako, Y. Nakano, K. Kojima-Aikawa, B. Mannervik, S. Shuto, Y. Ito, R. Morgensten, H. Abe, ChemBioChem 13 (2012) 1428-1432.

117.F. Bonvicini, M. Mirasoli, G. Gallinella, M. Zerbini, M. Musiani, A. Roda, Analyst 132 (2007) 519-523.

118.(a) Z. Li, W. Li, Y. Cheng, L. Hao, Analyst 133 (2008) 1164-1168;(b) L. Xin, Z. Cao, C. Lau, M. Kai, J. Lu, Luminescence 25 (2010) 336-342.

119.M. Mirasoli, M. Guardigli, P. Simoni, S. Venturoli, S. Ambretti, M. Musiani, A. Roda, Anal. Bioanal. Chem. 394 (2009) 981-987.

120.(a) M.E. Roth-Konforti, C.R. Bauer, D. Shabat, Angew. Chem. Int. Ed. 56 (2017) 15633-15638;(b) L.S. Ryan, A.R. Lippert, Angew. Chem. Int. Ed. 57 (2018) 622-624.

121.J. Cao, R. Lopez, J.M. Thacker, J.Y. Moon, C. Jiang, S.N.S. Morris, J.H. Bauer, P. Tao, R.P. Masonc, A.R. Lippert, Chem. Sci. 6 (2015) $1979-1985$.

122.K.J. Bruemmer, O. Green, T.A. Su, D. Shabat, C.J. Chang, Angew. Chem. Int. Ed. 57 (2018) 7508-7512.

123.J.-A. Richard, L. Jean, A. Romieu, M. Massonneau, P. Noack-Fraissignes, P.-Y. Reanrd, Org. Lett. 9 (2007) 4853-4855.

124.V. Bassaneze, A.A. Miyakawa, J.E. Krieger, Anal. Biochem. 372 (2008) 198-203.

125.J. Cao, J. Campbell, L. Liu, R.P. Mason, A.R. Lippert, Anal. Chem. 88 (2016) 4995-5002.

126.L.S. Selvakumar, M.S. Thakur, Anal. Chim. Acta 722 (2012) 107-113.

127.J.-B. Li, Q. Wang, H.-W. Liu, L. Yuan, X.-B. Zhang, Chem. Commun. 55 (2019) 4487-4490. 